\title{
Genome Mining-Driven Discovery of 5-Methylorsellinate-Derived Meroterpenoids from Aspergillus funiculosus
}

Dexiu Yan ${ }^{\dagger}$ and Yudai Matsuda*,†

'Department of Chemistry, City University of Hong Kong, Tat Chee Avenue, Kowloon, Hong Kong SAR, China

*Correspondence should be addressed to Yudai Matsuda (ymatsuda@cityu.edu.hk).

\section{Table of Contents}

Supplementary Materials and Methods

Supplementary Tables S1-S9

S6-S13

Supplementary Figures S1- S29

S14-S39

X-Ray Crystallographic Data

S40-S41

Supplementary References

S42 


\section{Supplementary Materials and Methods}

\section{General}

Organic solvents were purchased from Anaqua (Hong Kong) Co. Ltd., and other chemicals were purchased from Wako Chemicals Ltd., Thermo Fisher Scientific, Sigma-Aldrich, or J\&K Scientific Ltd., unless noted otherwise. Oligonucleotide primers (Table S3) were purchased from Tech Dragon Limited. PCR was performed using a T100 ${ }^{\mathrm{TM}}$ Thermal Cycler (Bio-Rad Laboratories, Inc.) with Phanta Max Super-Fidelity DNA Polymerase (Vazyme Biotech Co., Ltd) or Phusion ${ }^{\mathrm{TM}}$ High-Fidelity DNA Polymerase (Thermo scientific). DNA Sequencing analyses were performed by Tech Dragon Ltd. Analytical HPLC was performed on a Dionex Ultimate 3000 UHPLC system (Thermo Scientific), using a Kinetex $2.6 \mu \mathrm{m} \mathrm{C}_{18} 100 \AA$ column (2.1 i.d. x 100 mm; Phenomenex) for the products from in vivo experiments and an Accucore ${ }^{\mathrm{TM}} \mathrm{C} 18$ column (4.6 i.d. x $100 \mathrm{~mm}$; Thermo Scientific) for the products from in vitro experiments. Preparative HPLC was performed on a Waters 1525 Binary HPLC pump with a 2998 photodiode array detector (Waters Corporation), using a an XBridge BEH C18 OBD Prep Column (100 $\AA, 5 \mu \mathrm{m}, 19$ i.d. x 250 mm; Waters Corporation). Flash chromatography was performed using an Isolera Spektra One flash purification system (Biotage). NMR spectra were obtained 600 $\mathrm{MHz}\left({ }^{1} \mathrm{H}\right) / 150 \mathrm{MHz}\left({ }^{13} \mathrm{C}\right)$ with a Bruker Ascend Avance III HD spectrometer, and chemical shifts were recorded with reference to solvent signals ( ${ }^{1} \mathrm{H}$ NMR: $\mathrm{CDCl}_{3} 7.26 \mathrm{ppm}$, DMSO- $d_{6} 2.49 \mathrm{ppm}, \mathrm{CD}_{3} \mathrm{OD} 3.31 \mathrm{ppm} ;{ }^{13} \mathrm{C} \mathrm{NMR}$ : $\left.\mathrm{CDCl}_{3} 77.0 \mathrm{ppm}, \mathrm{DMSO}-d_{6} 39.5 \mathrm{ppm}, \mathrm{CD}_{3} \mathrm{OD} 49.0 \mathrm{ppm}\right)$. HR-ESI-MS spectra were obtained with a micrOTOF-Q II mass spectrometer (Bruker Daltonics). Optical rotations were measured with P-2000 Digital Polarimeter (JASCO Corporation). X-ray diffraction data were collected on a Bruker D8 Venture Photon II diffractometer.

\section{Strains}

Aspergillus funiculosus CBS 116.56 was purchased from the Westerdijk Fungal Biodiversity Institute and used as a source for the cloning of each gene in the $f n c$ cluster. Aspergillus oryzae NSAR1 (niaD-, $\left.s C^{-}, \triangle \arg B, \operatorname{ade} A^{-}\right)^{1}$ was utilized as the fungal heterologous expression host. Standard DNA engineering was performed with Escherichia coli DH5a (Takara Bio Inc). E. coli Transetta(DE3) (TransGen Biotech Co., Ltd.) was used for the expression of FncG.

\section{Construction of fungal transformation plasmids}

To construct fungal expression plasmids for $A$. oryzae, each gene in the $f n c$ cluster was first amplified from the genomic DNA of A. funiculosus CBS 116.56 with the primers described in Tables S3 and S4. Upon the constructions of the transformation plasmids, the database sequence of some $f n c$ genes were manually added or revised (Table S2). Each amplified DNA fragment was then introduced into pTAex3 vector ${ }^{2}$ except for $f n c D$, while $f n c D$ is ligated into the pUSA vector, ${ }^{3}$ using a ClonExpress Ultra One Step Cloning Kit (Vazyme Biotech 
Co., Ltd). For the construction of multigene-containing plasmids, DNA fragments harboring the amy $B$ promoter $(P a m y B)$ and the $a m y B$ terminator $($ TamyB) were amplified from the pTAex3-based plasmids, and further introduced into the already constructed single gene-containing vector or other vectors, pAdeA ${ }^{4}$ or pPTRI. ${ }^{5}$ Detailed methods for the construction of the plasmids used in this study are summarized in Table S4.

\section{Fungal transformation}

Transformation of $A$. oryzae was carried out by the previously reported protoplast-polyethylene glycol method, ${ }^{6}$ and the transformants created in this study and the plasmids used for the transformation are given in Table S5. Briefly, for the introduction of $f n c E, f n c D, f n c B, f n c A, f n c H, f n c C, f n c G$, and $f n c F, A$. oryzae NSAR1 was initially transformed with three plasmids pTAex3-fncE, pUSA-fncD $+B+A, p A d e A-f n c H+C$. The resultant transformant was further transformed using the plasmid pPTRI-fncG $+F$ to construct the eight gene-expressing transformant. To construct the transformants not expressing one or more genes, some of the plasmids were not used, or the plasmids containing only one gene were used upon performing the transformation.

\section{HPLC analysis of each product from A. oryzae transformants.}

Metabolites from each transformants were analyzed by HPLC, with a solvent system of $20 \mathrm{mM}$ formic acid (solvent A) and acetonitrile containing $20 \mathrm{mM}$ formic acid (solvent B), at a flow rate of $0.4 \mathrm{~mL} / \mathrm{min}$ and a column temperature of $40^{\circ} \mathrm{C}$. Separation was performed using a linear gradient from 10:90 (solvent B/solvent A) to $100: 0$ for $10 \mathrm{~min}, 100: 0$ for the following $3 \mathrm{~min}$, and a linear gradient from 100:0 to 10:90 within the following $2.0 \mathrm{~min}$, and then 10:90 for $2.5 \mathrm{~min}$ of equilibrium.

\section{Isolation of each metabolite.}

To isolate each metabolite, A. oryzae transformants were cultivated on 30 DPY agar plates $[c a .600 \mathrm{~mL} ; 2 \%$ dextrin, $1 \%$ hipolypepton (Nihon Pharmaceutical Co., Ltd.), $0.5 \%$ yeast extract, $0.5 \% \mathrm{KH}_{2} \mathrm{PO}_{4}, 0.05 \%$ $\mathrm{MgSO}_{4} \cdot 7 \mathrm{H}_{2} \mathrm{O}$, and $1.5 \%$ agar] for seven days at $30{ }^{\circ} \mathrm{C}$. The resulting fungal cultures, including agar medium, were crushed into small pieces, soaked in ethyl acetate, and extracted twice using an ultrasonic bath. After filtration, ethyl acetate was removed in vacuo. The residue was fractionated by flash chromatography, and further purified by preparative HPLC. Purification methods for each compound are described in detail below.

\section{Purification conditions for funiculolide A (1):}

The extract from $A$. oryzae NSAR1 with $f n c E, f n c D, f n c B, f n c A, f n c H$, and $f n c C$ (250 mg) was subjected to flash chromatography and eluted stepwise using a dichloromethane:ethyl acetate gradient (100:0 to 0:100). Fractions that contained 1 were then purified by reverse-phase preparative HPLC (48\% aqueous acetonitrile, 10.0 $\mathrm{mL} / \mathrm{min}$ ) to yield $30.2 \mathrm{mg}$ of a yellowish solid. 


\section{Purification conditions for funiculolides B (2), C (3), and D (4):}

The extract from $A$. oryzae NSAR1 with $f n c E, f n c D, f n c B, f n c A, f n c H, f n c C, f n c G$, and $f n c F(300 \mathrm{mg})$ was subjected to flash chromatography and eluted stepwise using a dichloromethane:ethyl acetate gradient (100:0 to $0: 100$ ). Fractions that contained 2 were then purified by reverse-phase preparative HPLC ( $48 \%$ aqueous acetonitrile, $10.0 \mathrm{~mL} / \mathrm{min}$ ) to yield $8.0 \mathrm{mg}$ of a colorless crystal. Fractions that contained 3 were then purified by reverse-phase preparative HPLC ( $38 \%$ aqueous acetonitrile, $10.0 \mathrm{~mL} / \mathrm{min}$ ) to yield $13.2 \mathrm{mg}$ of a colorless crystal (3) and $0.3 \mathrm{mg}$ of white amorphous solid (4).

\section{Expression and purification of FncG}

To express $f n c G$ in $E$. coli, the $f n c G$ gene was amplified from the genomic DNA of $A$. funiculosus CBS 116.56 and then ligated into the pET-28a(+) vector (Novagen), using a ClonExpress Ultra One Step Cloning Kit (Table S4). For the expression of FncG, E. coli Transetta (DE3) was transformed using the above-constructed pET$28 \mathrm{a}(+)$-based plasmid. The E. coli transformant was first cultivated using shaking at $37{ }^{\circ} \mathrm{C} / 160 \mathrm{rpm}$, in $\mathrm{LB}$ medium containing $50 \mathrm{mg} / \mathrm{L}$ kanamycin sulfate and $34 \mathrm{mg} / \mathrm{L}$ chloramphenicol. When the cultures reached an $\mathrm{OD}_{600}$ of $0.55,0.5 \mathrm{mM}$ IPTG was added to induce the gene expression, followed by further incubation for $19 \mathrm{~h}$ at $16{ }^{\circ} \mathrm{C} / 200 \mathrm{rpm}$. Protein purification was performed as previously described. ${ }^{6}$ The purity of each purified protein was examined by sodium dodecyl sulfate polyacrylamide gel electrophoresis (SDS-PAGE) (Figure S5), and the protein concentrations were determined with a NanoDrop ${ }^{\mathrm{TM}} \mathrm{One}^{\mathrm{C}}$ spectrophotometer (Thermo Scientific).

\section{Enzymatic reaction assay of FncG}

All of the analytical scale-enzymatic reactions were conducted in $50 \mu \mathrm{L}$ reaction mixtures at $30{ }^{\circ} \mathrm{C}$ for $1 \mathrm{~h}$, and terminated by the addition of $50 \mu \mathrm{L}$ of methanol and vortex mixing. The supernatant obtained after centrifugation was analyzed by HPLC (45\% aqueous acetonitrile containing $20 \mathrm{mM}$ formic acid, $1.0 \mathrm{~mL} / \mathrm{min}$ ). The standard enzymatic reaction of FncG with funiculolide A (1), funiculolide B (2), or funiculolide C (3) was performed in reaction mixtures containing $50 \mathrm{mM}$ Tris- $\mathrm{HCl}$ buffer $(\mathrm{pH} 7.5), 0.5 \mathrm{mM}$ of $\mathbf{1}$, 2, or 3, $0.1 \mathrm{mM}$ $\mathrm{FeSO}_{4}, 2.5 \mathrm{mM} \alpha$-ketoglutarate, $4 \mathrm{mM}$ ascorbate, and $10.7 \mu \mathrm{M}$ FncG, for $1 \mathrm{~h}$. When required, $1 \mathrm{mM}$ EDTA was added to the reaction.

\section{Production and purification of funiculolide D (4)}

The purified FncG (final conc. $14 \mu \mathrm{M}$ ) was added to $210 \mathrm{~mL}$ of reaction buffer $(50 \mathrm{mM}$ Tris-HCl buffer $\mathrm{pH} 7.5$, $0.1 \mathrm{mM} \mathrm{FeSO}_{4}, 2.5 \mathrm{mM} \alpha$-ketoglutarate, $4 \mathrm{mM}$ ascorbate) and incubated with $0.5 \mathrm{mM}$ funiculolide $\mathrm{C} \mathrm{(3)}$ at $30{ }^{\circ} \mathrm{C}$ for $1 \mathrm{~h}$. To purify 4 , the reaction mixture was loaded onto Sep-Pak C18 plus short cartridge (Waters Corporation) and eluted stepwise using a water:methanol gradient (100:0 to 0:100). The fraction containing 4 was concentrated to yield $5.4 \mathrm{mg}$ of white amorphous solid. 


\section{Structural determination of funiculolide D (4)}

The molecular formula of $\mathbf{4}$ was determined as $\mathrm{C}_{24} \mathrm{H}_{32} \mathrm{O}_{7}$ by HR-MS analysis. The NMR spectra of $\mathbf{4}$ was somewhat similar to those of $\mathbf{3}$, especially for the signals derived from the $\mathrm{C}, \mathrm{D}$, and E-rings, establishing the $\mathrm{C}, \mathrm{D}$, and E-rings of $\mathbf{4}$ to be the same as those of $\mathbf{3}$. However, the ${ }^{1} \mathrm{H}$ and ${ }^{13} \mathrm{C}$ NMR spectra of $\mathbf{4}$ revealed the disappearance of one of the methyl signals and the appearance of one oxymethine signal at $\mathrm{C}-13\left(\delta_{\mathrm{H}} / \delta_{\mathrm{C}}\right.$ 4.24/77.5). Interpretation of the ${ }^{1} \mathrm{H}-{ }^{1} \mathrm{H}$ COSY spectrum then revealed the spin systems of $\mathrm{H}-1 / \mathrm{H}-2$ and $\mathrm{H}-4 / \mathrm{H}-$ $14 / \mathrm{H}-15$. Furthermore, the HMBC correlations of $\mathrm{H}-2 \alpha(\delta 2.19)$ to $\mathrm{C}-3$ and $\mathrm{C}-13, \mathrm{H}-5(\delta 1.50)$ to C-1, C-10, C13, and C-15, and $\mathrm{H}-13$ ( $\delta$ 4.24) to C-2, C-3, C-5, and C-10 revealed the connections of C-3 to C-2 and C-13, C-4 to C-5, and C-10 to C-1, C-5, and C-13. Thus, it was elucidated that the cyclopentanone A-ring is spirofused to the B-ring at the $\mathrm{C}-10$ position. The stereochemistry at C-13 was determined based on the NOESY correlation of H-13 and H-4/H-14. Further analysis of 2D NMR spectra of 4 confirmed the structure of 4 as shown in Figure 3B.

\section{Analytical data}

Funiculolide $A$ (1). Yellowish solid; $[\alpha]^{23}{ }_{\mathrm{D}}-40.9\left(c 0.5, \mathrm{CHCl}_{3}\right)$; for NMR data see Table S6 and Figures S6 to S11; HRMS (ESI) $m / z$ : $[\mathrm{M}+\mathrm{H}]^{+}$Calcd for $\mathrm{C}_{24} \mathrm{H}_{31} \mathrm{O}_{5}$ 399.2166; Found 399.2165.

Funiculolide $B$ (2). Colorless crystal; $[\alpha]^{23}{ }_{\mathrm{D}}-252.3\left(\right.$ c $\left.0.23, \mathrm{CHCl}_{3}\right)$; for NMR data see Table $\mathrm{S} 7$ and Figures S12 to S17; HRMS (ESI) $m / z$ : $[\mathrm{M}+\mathrm{H}]^{+}$Calcd for $\mathrm{C}_{24} \mathrm{H}_{33} \mathrm{O}_{5}$ 401.2323; Found 401.2314.

Funiculolide $C$ (3). Colorless crystal; $[\alpha]^{23}{ }_{\mathrm{D}}-224.5$ ( $c$ 0.32, MeOH); for NMR data see Table S8 and Figures $\mathrm{S} 18$ to S23; HRMS (ESI) $m / z$ : $[\mathrm{M}+\mathrm{H}]^{+}$Calcd for $\mathrm{C}_{24} \mathrm{H}_{33} \mathrm{O}_{6} 417.2272$; Found 417.2279.

Funiculolide $D$ (4). White amorphous solid; $[\alpha]^{23}{ }_{\mathrm{D}}-281.1($ c $0.18, \mathrm{MeOH})$; for NMR data see Table S9 and Figures S24 to S29; HRMS (ESI) $m / z$ : [M + H] $]^{+}$Calcd for $\mathrm{C}_{24} \mathrm{H}_{33} \mathrm{O}_{7} 433.2221$; Found 433.2219.

\section{X-ray crystallographic analysis of funiculolides B (2) and C (3)}

Single crystal of compounds $\mathbf{2}$ and $\mathbf{3}$ were grown in $\mathrm{CH}_{3} \mathrm{OH} / \mathrm{CH}_{2} \mathrm{Cl}_{2}(2: 1, \mathrm{v} / \mathrm{v})$ by a slow evaporation process at room temperature. Single crystal X-ray diffraction measurements were performed on a Bruker D8 Venture diffractometer using $\mathrm{Cu} \mathrm{K \alpha}$ radiation at $243 \mathrm{~K}$. The data collection was performed with the APEX3 program, and cell refinement and data reduction were carried out using the SAINT program. The structures of $\mathbf{2}$ and $\mathbf{3}$ were solved by direct method with the SHELXT program and refined using the SHELXL program. All nonhydrogen atoms were refined anisotropically, whereas hydrogen atoms were placed by geometrical calculations. Absolute configuration of $\mathbf{2}$ and $\mathbf{3}$ was determined by the Flack parameters. 
Table S1. Annotation of each gene in the $f n c$ cluster.

The fnc cluster from Aspergillus funiculosus CBS 116.56

ca. $19.4 \mathrm{~kb}$

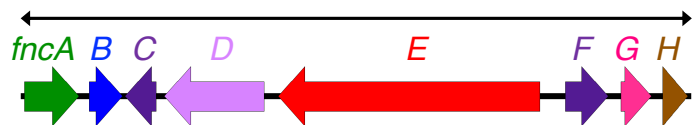

\begin{tabular}{cccccc}
\hline Gene & Protein ID & Amino acids (base pairs) & Protein homologue (origin) & Similarity/ldentity (\%) & Proposed function \\
\hline$f n c A$ & 210960 & $475(1607)$ & AndE (Emericella variecolor) & $75 / 57$ & FAD-dependent monooxygenase \\
$f n c B$ & 213769 & $324(975)$ & AndD (Emericella variecolor) & $66 / 48$ & prenyltransferase \\
$f n c C$ & - & $251(922)$ & AndC (Emericella variecolor) & $77 / 64$ & short-chain dehydrogenase/reductase \\
$f n c D$ & 213771 & $864(2928)$ & AndK (Emericella variecolor) & $75 / 60$ & $\begin{array}{c}\text { cytochrome P450 monooxygenase/hydrolase } \\
\text { non-reducing polyketide synthase } \\
\text { (SAT-KS-AT-PT-ACP-CMeT-TE) }\end{array}$ \\
$f n c E$ & 210963 & $2462(7671)$ & AndM (Emericella variecolor) & $69 / 53$ & short-chain dehydrogenase/reductase \\
$f n c F$ & 210964 & $399(1260)$ & SirQ (Leptosphaeria maculans) & $55 / 33$ & Fe(II)/KG-dependent dioxygenase \\
$f n c G$ & 210965 & $296(891)$ & AndA (Emericella variecolor) & $60 / 39$ & $74 / 54$ \\
$f n c H$ & 210966 & $221(729)$ & AndB (Emericella variecolor) & terpene cyclase
\end{tabular}

Note: Protein IDs are as designated in the JGI database. The $f n c C$ gene was not included in the filtered models available at JGI. The sequences of $f n c D$ and $f n c H$ were revised in this study (see Table S2).

Table S2. Newly predicted or revised DNA and protein sequences. Highlighted in magenta are the regions predicted for an intron in this study.

\begin{tabular}{|c|c|c|}
\hline Gene & Predicted/revised DNA sequence & Predicted/revised protein sequence \\
\hline fncC & $\begin{array}{l}\text { ATGTCACCCACCAAGAGTACTGCGGTATATAACTTACAGAATAAGGTCCTCATCATCA } \\
\text { CCGGCAGCTCATCCGGAATCGGGCTCGCAACGGCCTCAGCAGCTCTATCCGAAGG } \\
\text { CGCAAAAGTAGTAGGAACCGACATCCTCTCACCACCAGCCTCACTCCTCGAACACA } \\
\text { CCAACTTCCGCTTTGTCCCGGGCGATCTGACCCATCACTCGACTATCCAGGAGGTC } \\
\text { GTGGCGACCTGCACCGCCGCCTTGGTCGACGCCTGGACGGGCTGCTGAACGTC } \\
\text { GCCGGCGTCGCCGATCACTTTGGTAGTGTGGACAGCGTGTCCGACGAGCTCTGG } \\
\text { GAGAGGTGTCTGGCGGTCAACCTGACGGCTCCGGTGAAGCTCATGCGCGAGGCC } \\
\text { ATCCCTCTTATGCGCGAGCAGAAGAGCGGCAGCATCGTGAATGTCTCCAGCAAGG } \\
\text { CGGGTTTGAGCGGTGCTGCTGCTGGGGTTGCCTACACCGCTAGTACGTTCCTCAC } \\
\text { TCCACGTCTACGGATTCGATCTACAGCGTTCGGGGGAGTCAGAAGGGAAAAGCTG } \\
\text { GACTGACACTAGTTGTTCTAGGCAAACACGGTCTCATCGGGGCTACGAAAACGTC } \\
\text { GCGTGGAGGTTCAAGGATGAGATATCCGCTGCAACGCGGTCTGTCCTGGAGGTG } \\
\text { AGATCAACCTAGCGTATCTAGAAGACAGGCTAATGGCATCATAGGCGTTCCCACCG } \\
\text { GCTTCGGAAAAGAATCGAATACCTCCTGTGATCTCGACGCCCTCGCAGCTTTGCAG } \\
\text { CCCATCTACGCGGCGCACATGCCGGATGGCGAGCCTACGATTTCGCCCGAGGAGG } \\
\text { TGGCCAAACTGCTTCTCTTCCTGGTGTCTCCGCTGAGTGGGAAGATTACTGGAGC } \\
\text { GGTGATTCCTATAGACAATGCTTGGTCGACTATCTAG }\end{array}$ & $\begin{array}{l}\text { MSPTKSTAVLIITGSSSGIGLATASAALSEGAKVV } \\
\text { GTDILSPPASLLEHTNFRFVPGLTHHSTIQEVVA } \\
\text { TCTAAFGRRLDGLLNVAGVADHFGSVDSVSDEL } \\
\text { WERCLAVNLTAPVKLMREAIPLMREQKSGSIVNV } \\
\text { SSKAGLSGAAAGVAYTASKHGLIGATKNVAWRF } \\
\text { KDENIRCNAVCVPTGFGKESNTSCDLDALAALQ } \\
\text { PIYAAHMPDGEPTISPEEVAKLLLFLVSPLSGKIT } \\
\text { GAVIPIDNAWSTI }\end{array}$ \\
\hline$f n c D$ & $\begin{array}{l}\text { ATGTCTCTTCTACCGTCGGTGCTCGCTCTTACAGTCCTCTCTGCGCTATATCTCGGA } \\
\text { TACCGCGTAGTTGCTCCTCTCTGGTCCCTTCGACATATACCAGGCCCCTTCTGGGC } \\
\text { GAAGTTCACGAACCTCCCCAGGGTCTGGTGGGTTAAGACTGGTCAAGCCCAACGA } \\
\text { ATCCACCAGGAACTACATGAGAAATATGGCGACGTAGTCAGATTTGGGCCGAATATG }\end{array}$ & $\begin{array}{l}\text { MSLLPSVLALTVLSALYLGYRVVAPLWSLRHIPGP } \\
\text { FWAKFTNLPRVWWVKTGQAQRIHQELHEKYGD } \\
\text { VVRFGPNMVSISDPAVLPIVYPNRMGFPKDFYK } \\
\text { TQRPYTPGVGAMPAVFNTQDEALHKSLRSPIAP }\end{array}$ \\
\hline
\end{tabular}




\begin{tabular}{|c|c|c|}
\hline & 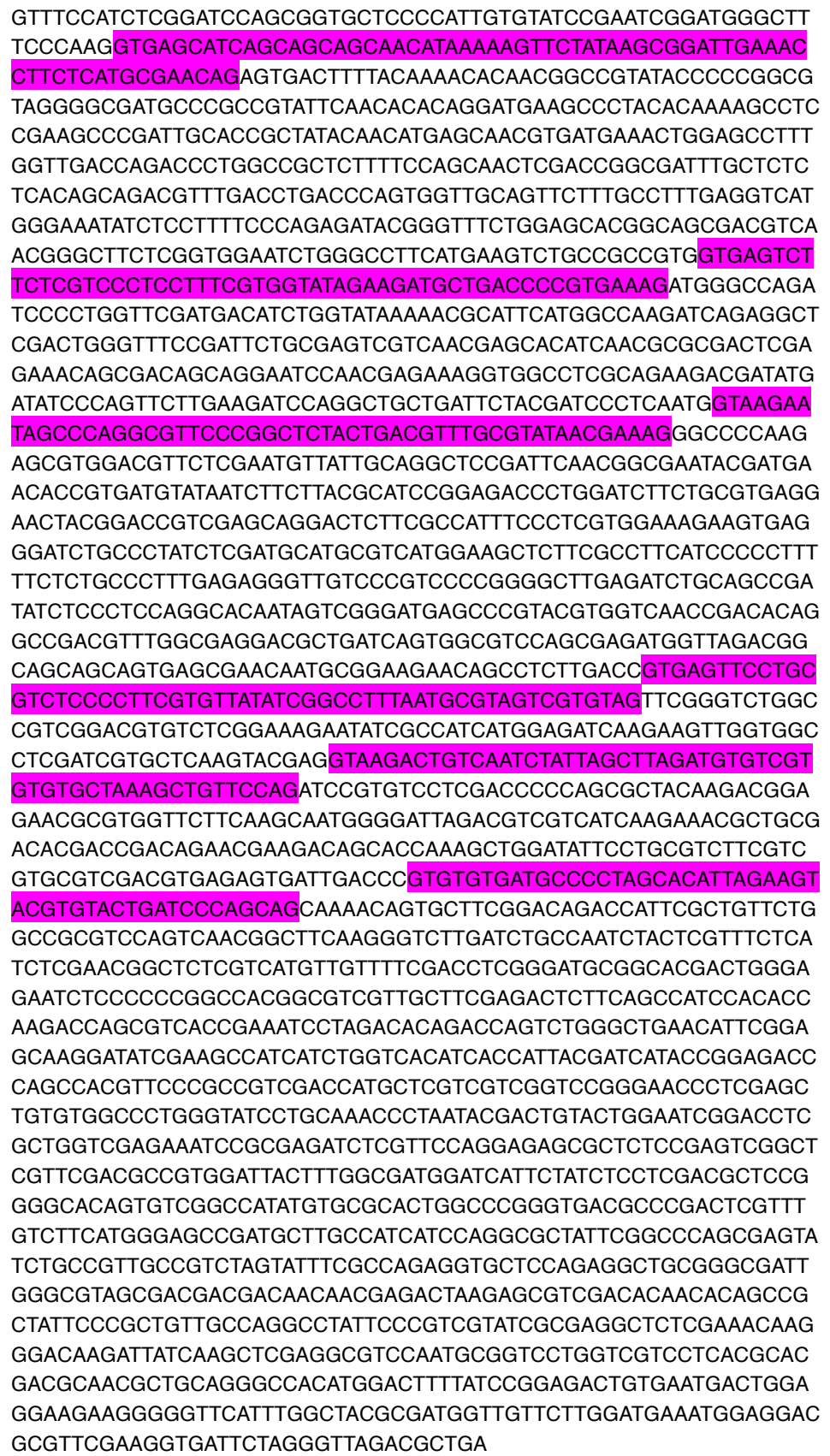 & $\begin{array}{l}\text { LYNMSNVMKLEPLVDQTLAALFQQLDRRFALSQ } \\
\text { QTFDLTQWLQFFAFEVMGNISFSQRYGFLEHGS } \\
\text { DVNGLLGGIWAFMKSAAVMGQIPWFDDIWYKNA } \\
\text { FMAKIRGSTGFPILRVVNEHINARLEKQRQQESN } \\
\text { EKGGLAEDDMISQFLKIQAADSTIPQWAPRAWT } \\
\text { FSNVIAGSDSTANTMNTVMYNLLTHPETLDLLRE } \\
\text { ELRTVEQDSSPFPSWKEVRDLPYLDACVMEALR } \\
\text { LHPPFSLPFERVVPSPGLEICSRYLPPGTIVGMS } \\
\text { PYVVNRHRPTFGEDADQWRPARWLDGSSSERT } \\
\text { MRKNSLLTFGSGRRTCLGKNIAIMEIKKLVASIVL } \\
\text { KYEIRVLDPQRYKTENAWFFQWGLDVVIKKRC } \\
\text { DTTDRTKTAPKLDIPASSSCVDVRVIDPKTVLRTD } \\
\text { HSLFWPRPVNGFKGLDLPIYSFLISNGSRHVVFD } \\
\text { LGMRHDWENLPPATASLLRDSSAIHTKTSVTEIL } \\
\text { DTDQSGLNIRSKDIEAIIWSHHHDHTGDPATFP } \\
\text { PSTMLVVGPGTLELCGPGYPANPNTTVLESDLA } \\
\text { GREIREISFQESALRVGSFDAVDYFGDGSFYLLD } \\
\text { APGHSVGHMCALARVTPDSFVFMGADACHHPG } \\
\text { AIRPSEYLPLPSSISPEVLQRLRAIGRSDDDNNET } \\
\text { KSVDTTQPLFPLLPGLFPSYREALETRDKIIKLEA } \\
\text { SNAVLVVLTHDATLQGHMDFYPETVNDWRKKGV } \\
\text { HLATRWLFLDEMEDAFEGDSRVRR* }\end{array}$ \\
\hline$H$ & $\begin{array}{l}\text { ATGAAGACTCTCCTGAAGACTCTCAGCCTGATCAACTCCGCAGGCTGGATGATCAA } \\
\text { CTACATCGGGATGGTCTACCTCTCCTTCAAGGACCAGACGTACAGTATGGCGATTAT } \\
\text { CCCTCTCTGCTGCAACGTCGCCTGGGAAATCGTCTACGGCATCATCCAGCCCAGCT } \\
\text { CAATCATTGTCCCGCGCAAGGTCATCCTCACCTGGCTCGCGTTAAACTGCGCGGTG } \\
\text { ATGTACGCTGCCATCAAGTTCGCTCCTACCGAGTGGTCGCATGCTCCGCTGGTCAT } \\
\text { GGAAACCTCCCTCTGATATTCGCGATTGGAGTTGCGGTGTTCATCGCGGGCCATC } \\
\text { TGGCTCTCGCTGCAGAGCTGGGCCCTCAGACAGCTTTCCTTTGGAGTGCGAGGGC } \\
\text { GTGTCAGACTCTGCTCAGCGTCGGGGCGCTTCTCCAGCTCCTTGGAAGGGGGAG } \\
\text { TACTCGCGGTGCCTCTTTCTTAGTATGGTGGGTTTCTTCTCATGGGATGGATAAGTT } \\
\text { TGTTATTGTTGTACGCGGAACTGACTTCAACAGGTTCTCTCGGTTCTTTGGTAGCGC } \\
\text { GTGTGGAGTTGTGAGGTTGTCGGTTATGTATCTACGCGGGATGCACTCGTTCGCCT } \\
\text { GGTTTAATAGTCCGTTGACGATGTGGTGTGTTGTTCTATTCTTGCTGTCGGACATGC } \\
\text { TGTATGGAGTGTGTTTCTACTACATTCGCGGCCGGGAGTTGAATCCGCCGGTATAG }\end{array}$ & $\begin{array}{l}\text { MKTLLKTLSLINSAGWMINYIGMVYLSFKDQTYS } \\
\text { MAIIPLCCNVAWEIVYGIIQPSSIIVPRKVILTWLAL } \\
\text { NCAVMYAAIKFAPTEWSHAPLVMENLPLIFAIGVA } \\
\text { VFIAGHLALAAELGPQTAFLWSARACQTLLSVGA } \\
\text { LLQLLGRGSTRGASFLVWFSRFFGSACGVVRS } \\
\text { VMYLRGMHSFAWFNSPLTMWCVVLFLLSDMLY } \\
\text { GVCFYYIRGRELNPPV* }\end{array}$ \\
\hline
\end{tabular}


Table S3. Primers used in this study.

\begin{tabular}{|c|c|}
\hline Primer & Sequence $\left(5^{\prime}\right.$ to $\left.3^{\prime}\right)$ \\
\hline fncA-F & TCGAGCTCGGTACCCATGGAGAGCCCTAGATTCAGAG \\
\hline fncA-R & CTACTACAGATCCCCGAGGTTGAGATCGATAGACGGC \\
\hline fncB-F & TCGAGCTCGGTACCCAATGGCCGTGGACAAGCAAAGC \\
\hline fncB-R & CTACTACAGATCCCCTGCAGTGTATTCCATTCCCAC \\
\hline fncC-F & TCGAGCTCGGTACCCATGTCACCCACCAAGAGTACTGC \\
\hline fncC-R & CTACTACAGATCCCCTAGATAGTCGACCAAGCATTGTC \\
\hline fncD-F1 & TCGAGCTCGGTACCCCAGTGCAATGTCTCTTCTACCG \\
\hline fncD-R1 & ATGCATCGAGATAGGGCAGATC \\
\hline fncD-F2 & CTATCTCGATGCATGCGTCATG \\
\hline fncD-R2 & CTACTACAGATCCСTGCATAGTACGGGTCTGTCTAC \\
\hline fncE-F1 & TCGAGCTCGGTACCCAGGATGGGCTCATTACCAGAG \\
\hline fncE-R1 & GAATGGAACGCATGGGTGTTGGTC \\
\hline fncE-F2 & CCATGCGTTCCATTCCAGACTGGTC \\
\hline fncE-R2 & CTACTACAGATCCCCAGTAGAACCAGCTAAAGTACAGC \\
\hline fncF-F & TCGAGCTCGGTACCCACGATGACTTCTGGAAAC \\
\hline fncF-R & CTACTACAGATCCCCAGTTGCCATCATGGAATGATTCG \\
\hline fncG-F & TCGAGCTCGGTACCCATGACTGTCATTCCCTGTGATAGAC \\
\hline fncG-R & CTACTACAGATCCCCACAGCAGCAAGGATCTCATAC \\
\hline fncH-F & TCGAGCTCGGTACCCAGCACAATGAAGACTCTCCTG \\
\hline fncH-R & CTACTACAGATCCCCAGTCTTAGCCAAACTTGC \\
\hline InF-pUSA_Xbal-F & GAAAGGATCCTCTAGCCCATCATGGTGTTTTGATC \\
\hline InF_pUSA_Xbal_R & CCAAGATGACTCTAGGTAAGATACATGAGCTTCGG \\
\hline InF_pAdeA_Xbal_F & GCAGGTCGACTCTAGCCCATCATGGTGTTTTGATC \\
\hline InF_pAdeA_Xbal_R & TAGTAGATCCTCTAGGTAAGATACATGAGCTTCGG \\
\hline InF-pPTRI_Smal-F & CTCTAGAGGATCCCCATCATGGTGTTTTGATC \\
\hline InF-pPTRI_Smal-R & TCGAGCTCGGTACCCGTAAGATACATGAGCTTCGG \\
\hline InF-linker-F1 & GCTCGCGAGCGCGTTCCACTGCATCATCAGTCTAG \\
\hline InF-linker-R1 & AACGCGCTCGCGAGCAAGTACCATACAGTACCGCG \\
\hline Ndel_fncG-F & CGCGCGGCAGCCATATGACTGTCATTCCCTGTGATAGAC \\
\hline EcoRI_fncG-R & GACGGAGCTCGAATTACTGCACCTTTGCGGCGGATTTC \\
\hline
\end{tabular}


Table S4. Plasmids constructed in this study and PCR conditions for the amplification of the inserts for the plasmid constructions.

\begin{tabular}{|c|c|c|c|c|c|}
\hline Plasmid & Inserts & Primer 1 & Primer 2 & PCR Template & Vector \\
\hline pTAex3-fncE & $\begin{array}{l}1^{\text {st }} \text { half of } f n c E \\
2^{\text {nd }} \text { half of } f n c E\end{array}$ & $\begin{array}{l}\text { fncE-F1 } \\
\text { fncE-F2 }\end{array}$ & $\begin{array}{l}\text { fncE-R1 } \\
\text { fncE-R2 }\end{array}$ & gDNA & pTAex3 digested with Smal \\
\hline pTAex3-fncB & $f n c B$ & fncB-F & fncB-R & gDNA & pTAex3 digested with Smal \\
\hline pTAex3-fncA & $f n c A$ & fncA-F & fncA-R & gDNA & pTAex3 digested with Smal \\
\hline pTAex3-fncH & $\mathrm{fncH}$ & fncH-F & fnch-R & gDNA & pTAex3 digested with Smal \\
\hline pTAex3-fncC & fncC & fncC-F & fncC-R & gDNA & pTAex3 digested with Smal \\
\hline pTAex3-fncF & fncF & fncF-F & fncF-R & gDNA & pTAex3 digested with Smal \\
\hline pTAex3-fncG & fncG & fncG-F & fncG-R & gDNA & pTAex3 digested with Smal \\
\hline pUSA-fncD & $\begin{array}{l}1^{\text {st }} \text { half of } f n c D \\
2^{\text {nd }} \text { half of } f n c D\end{array}$ & $\begin{array}{l}\text { fncD-F1 } \\
\text { fncD-F2 }\end{array}$ & $\begin{array}{l}\text { fncD-R1 } \\
\text { fncD-R2 }\end{array}$ & gDNA & pUSA digested with Smal \\
\hline$p U S A-f n c D+f n c B+f n c A$ & $\begin{array}{l}\text { PamyB-fncB-TamyB } \\
\text { PamyB-fncA-TamyB }\end{array}$ & $\begin{array}{l}\text { In-pUSA_Xbal-F } \\
\text { InF-linker-F1 }\end{array}$ & $\begin{array}{l}\text { InF-linker-R1 } \\
\text { In-pUSA_Xbal-R }\end{array}$ & $\begin{array}{l}\text { pTAex3-fncB } \\
\text { pTAex3-fncA }\end{array}$ & pUSA-fncD digested with $X b a l$ \\
\hline PAdeA-fncH+fncC & $\begin{array}{l}\text { PamyB-fncH-TamyB } \\
\text { PamyB-fncC-TamyB }\end{array}$ & $\begin{array}{l}\text { In-pAdea_Xbal-F } \\
\text { InF-linker-F1 }\end{array}$ & $\begin{array}{l}\text { InF-linker-R1 } \\
\text { In-pAdea_Xbal-R }\end{array}$ & $\begin{array}{l}\text { pTAex3-fncH } \\
\text { pTAex3-fncC }\end{array}$ & pAdeA digested with $X$ bal \\
\hline pPTRI-fncF & PamyB-fncF-TamyB & In-pPTRI_Smal-F & In-pPTRI_Smal-R & pTAex3-fncF & pPTRI digested with Smal \\
\hline pPTRI-fncG & PamyB-fncG-TamyB & In-pPTRI_Smal-F & In-pPTRI_Smal-R & pTAex3-fncG & pPTRI digested with Smal \\
\hline pPTRI-fncF+fncG & $\begin{array}{l}\text { PamyB-fncF-TamyB } \\
\text { PamyB-fncG-TamyB }\end{array}$ & $\begin{array}{l}\text { In-pPTRI_Smal-F } \\
\text { InF-linker-F1 }\end{array}$ & $\begin{array}{l}\text { InF-linker-R1 } \\
\text { In-pPTRI_Smal-R }\end{array}$ & $\begin{array}{l}\text { pTAex3-fncF } \\
\text { pTAex3-fncG }\end{array}$ & pPTRI digested with Smal \\
\hline pET-28a(+)-fncG & fncG & Ndel_fncG-F & EcoRI_fncG-R & gDNA & $\begin{array}{l}\text { pET-28a }(+) \text { digested with } \mathrm{Ndel} \text { and } \\
\text { EcoRI }\end{array}$ \\
\hline
\end{tabular}

Table S5. Aspergillus oryzae transformants constructed in this study.

\begin{tabular}{|l|l|l|}
\hline Strain & Host strain & Plasmids used for transformation \\
\hline A. oryzae / fncEDBAHC & A. oryzae NSAR1 & pTAex3-fncE, pUSA-fncD+B+A, pAdeA-fncH+C \\
\hline A. oryzae / fncEDBAHCF & A. oryzae / fncEDBAHC & pPTRI-fncF \\
\hline A. oryzae / fncEDBAHCG & A. oryzae / fncEDBAHC & pPTRI-fncG \\
\hline A. oryzae / fncEDBAHCFG & A. oryzae / fncEDBAHC & pPTRI-fncF+G \\
\hline
\end{tabular}


Table S6. NMR data for funiculolide A (1).

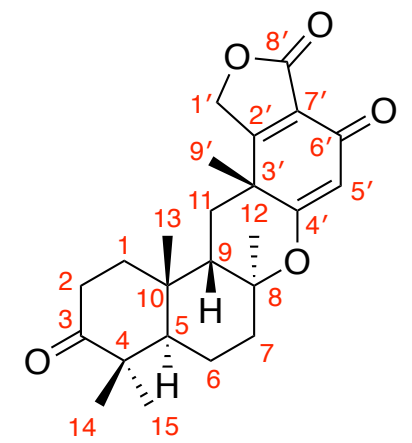

\begin{tabular}{|c|c|c|c|c|c|}
\hline position & $\delta_{c}$, type & $\delta_{\mathrm{H}}$, mult. $(\mathrm{J}$ in $\mathrm{Hz})$ & HMBC correlation & COSY correlation & NOESY correlation \\
\hline \multirow[t]{2}{*}{1} & $30.4, \mathrm{CH}_{2}$ & $1.87(a), \operatorname{td}(12.7,2.8)$ & & $\mathrm{H}-2 \mathrm{a}, \mathrm{H}-2 \beta$ & $\mathrm{H}-2 \mathrm{a}$ \\
\hline & & $1.42(\beta)$, ddd $(12.8,9.9,5,5)$ & & $\mathrm{H}-2 \mathrm{a}, \mathrm{H}-2 \beta$ & $\mathrm{H}-2 \mathrm{a}, \mathrm{H}-2 \beta, \mathrm{H}-13$ \\
\hline \multirow[t]{2}{*}{2} & $33.0, \mathrm{CH}_{2}$ & $2.65(a)$, ddd $(16.1,12.1,5,5)$ & 1,3 & $\mathrm{H}-1 \mathrm{a}, \mathrm{H}-1 \beta$ & $\mathrm{H}-1 \mathrm{a}, \mathrm{H}-1 \beta, \mathrm{H}-15$ \\
\hline & & $2.35(\beta)$, ddd $(16.1,9.9,3.3)$ & 4 & $\mathrm{H}-1 \mathrm{a}, \mathrm{H}-1 \beta$ & $\mathrm{H}-1 \beta$ \\
\hline 3 & 217.6, C & & & & \\
\hline 4 & $46.8, \mathrm{C}$ & & & & \\
\hline 5 & 46.3, $\mathrm{CH}$ & $1.96 \mathrm{dd},(12.8,2.6)$ & $1,4,14$ & $\mathrm{H}-6 \mathrm{a}, \mathrm{H}-6 \beta$ & $\mathrm{H}-6 \mathrm{a}, \mathrm{H}-12, \mathrm{H}-15$ \\
\hline \multirow[t]{2}{*}{6} & $18.0, \mathrm{CH}_{2}$ & $1.64(a), m$ & & $\mathrm{H}-5, \mathrm{H}-7 \mathrm{a}, \mathrm{H}-7 \beta$ & $\mathrm{H}-5, \mathrm{H}-14, \mathrm{H}-15, \mathrm{H}-7 \mathrm{a}, \mathrm{H}-7 \beta$ \\
\hline & & $1.68(\beta), m$ & & $\mathrm{H}-5, \mathrm{H}-7 \mathrm{a}, \mathrm{H}-7 \beta$ & $\mathrm{H}-14, \mathrm{H}-7 \beta, \mathrm{H}-9$ \\
\hline \multirow[t]{2}{*}{7} & $37.4, \mathrm{CH}_{2}$ & $1.98(a)$, dt $(14.3,9.5)$ & 8,9 & $\mathrm{H}-6 \mathrm{a}, \mathrm{H}-6 \beta$ & $\mathrm{H}-6 \mathrm{a}, \mathrm{H}-12$ \\
\hline & & $2.22(\beta), \mathrm{dd}(14.3,8.4)$ & 5,8 & $\mathrm{H}-6 \mathrm{a}, \mathrm{H}-6 \beta$ & $\mathrm{H}-6 \mathrm{a}, \mathrm{H}-6 \beta$ \\
\hline 8 & $85.3, \mathrm{C}$ & & & & \\
\hline 9 & $43.7, \mathrm{CH}$ & $2.27 \mathrm{dd}(13.2,3.3)$ & & $\mathrm{H}-11 \mathrm{a}, \mathrm{H}-11 \beta$ & $\mathrm{H}-6 \beta, \mathrm{H}-13, \mathrm{H}-9^{\prime}$ \\
\hline 10 & $35.3, \mathrm{C}$ & & & & \\
\hline \multirow[t]{2}{*}{11} & $29.3, \mathrm{CH}_{2}$ & $1.83(a), t(13.2)$ & $9,2^{\prime}, 3^{\prime}, 9^{\prime}$ & $\mathrm{H}-9$ & $\mathrm{H}-12$ \\
\hline & & $1.73(\beta), \mathrm{dd}(12.8,3.3)$ & 9 & $\mathrm{H}-9$ & $\mathrm{H}-13, \mathrm{H}-1^{\prime} \mathrm{a}$ \\
\hline 12 & $25.6, \mathrm{CH}_{3}$ & $1.38, \mathrm{~s}$ & $7,8,9$ & & $H-5, H-7 a, H-11 a$ \\
\hline 13 & $22.1, \mathrm{CH}_{3}$ & $0.94, \mathrm{~s}$ & $1,5,9,10$ & & $\mathrm{H}-1 \beta, \mathrm{H}-9, \mathrm{H}-11 \beta$ \\
\hline 14 & $19.5, \mathrm{CH}_{3}$ & $1.08, \mathrm{~s}$ & $3,4,5,15$ & & $\mathrm{H}-6 \mathrm{a}, \mathrm{H}-6 \beta$ \\
\hline 15 & $29.1, \mathrm{CH}_{3}$ & $1.10, \mathrm{~s}$ & $3,4,5,14$ & & $\mathrm{H}-2 \mathrm{a}, \mathrm{H}-5, \mathrm{H}-6 \mathrm{a}$ \\
\hline \multirow[t]{2}{*}{$1^{\prime}$} & 66.7, $\mathrm{CH}_{2}$ & $4.97(a), d(18.3)$ & $2^{\prime}, 7^{\prime}, 8^{\prime}$ & & $\mathrm{H}-11 \beta$ \\
\hline & & $4.93(\beta), d(18.7)$ & $2^{\prime}, 7^{\prime}, 8^{\prime}$ & & $\mathrm{H}-9^{\prime}$ \\
\hline $2^{\prime}$ & $180.2, \mathrm{C}$ & & & & \\
\hline $3^{\prime}$ & $40.2, \mathrm{C}$ & & & & \\
\hline $4^{\prime}$ & $175.4, \mathrm{C}$ & & & & \\
\hline $5^{\prime}$ & $115.3, \mathrm{CH}$ & $5.86, \mathrm{~s}$ & $3^{\prime}, 4^{\prime}, 7^{\prime}$ & & $\mathrm{H}-9^{\prime}$ \\
\hline $6^{\prime}$ & 179.7, C & & & & \\
\hline $7^{\prime}$ & $122.0, \mathrm{C}$ & & & & \\
\hline $8^{\prime}$ & $167.1, \mathrm{C}$ & & & & \\
\hline $9^{\prime}$ & $27.1, \mathrm{CH}_{3}$ & $1.60, \mathrm{~s}$ & $11,2^{\prime}, 3^{\prime}, 4^{\prime}$ & & $H-9, H-1^{\prime} \beta, H-5^{\prime}$ \\
\hline
\end{tabular}

${ }^{1} \mathrm{H}$ NMR: $600 \mathrm{MHz},{ }^{13} \mathrm{C}$ NMR: $150 \mathrm{MHz}$ (in $\mathrm{CDCl}_{3}$ ) 
Table S7. NMR data for funiculolide B (2).

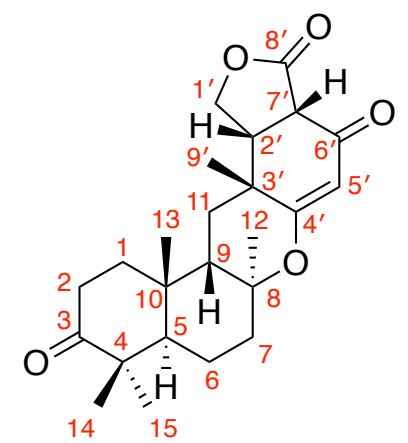

\begin{tabular}{|c|c|c|c|c|c|}
\hline position & $\delta_{c}$, type & $\delta_{\mathrm{H}}$, mult. $(\mathrm{J}$ in $\mathrm{Hz})$ & HMBC correlation & COSY correlation & NOESY correlation \\
\hline \multirow[t]{2}{*}{1} & $30.4, \mathrm{CH}_{2}$ & $1.91(a), m$ & 5,10 & $\mathrm{H}-2 \mathrm{a}, \mathrm{H}-2 \beta$ & $\mathrm{H}-2 \mathrm{a}, \mathrm{H}-11 \mathrm{a}$ \\
\hline & & $1.46(\beta), m$ & & $\mathrm{H}-2 \mathrm{a}, \mathrm{H}-2 \beta$ & $\mathrm{H}-2 \mathrm{a}, \mathrm{H}-2 \beta, \mathrm{H}-13$ \\
\hline \multirow[t]{2}{*}{2} & 33.1, $\mathrm{CH}_{2}$ & $2.65(a)$, ddd $(16.5,12.1,5.5)$ & 1,10 & $\mathrm{H}-1 \mathrm{a}, \mathrm{H}-1 \beta$ & $\mathrm{H}-1 \mathrm{a}, \mathrm{H}-1 \beta, \mathrm{H}-15$ \\
\hline & & $2.37(\beta)$, ddd $(16.19 .9,3.3)$ & $1,4,10$ & $\mathrm{H}-1 \mathrm{a}, \mathrm{H}-1 \beta$ & $\mathrm{H}-1 \beta$ \\
\hline 3 & 217.7, C & & & & \\
\hline 4 & $46.8, \mathrm{C}$ & & & & \\
\hline 5 & $46.5, \mathrm{CH}$ & $1.91, \mathrm{~m}$ & $6,7,13,14,15$ & $\mathrm{H}-6$ & $\mathrm{H}-12, \mathrm{H}-15$ \\
\hline 6 & $17.9, \mathrm{CH}_{2}$ & 1.62 & 5,10 & $\mathrm{H}-5, \mathrm{H}-7 \mathrm{a}, \mathrm{H}-7 \beta$ & \\
\hline \multirow[t]{2}{*}{7} & $37.5, \mathrm{CH}_{2}$ & $1.95(a), d t(14.3,9.5)$ & $6,8,9,12$ & $\mathrm{H}-6$ & $\mathrm{H}-12$ \\
\hline & & $2.16(\beta), \mathrm{dd}(13.9,8.1)$ & $5,6,8,12$ & $\mathrm{H}-6$ & $\mathrm{H}-9$ \\
\hline 8 & $83.5, \mathrm{C}$ & & & & \\
\hline 9 & $42.5, \mathrm{CH}$ & $2.11, \mathrm{dd}(12.8,2.9)$ & $1,7,8,10,12,13$ & $\mathrm{H}-11 \alpha, \mathrm{H}-11 \beta$ & $\mathrm{H}-7 \beta, \mathrm{H}-13, \mathrm{H}-9^{\prime}$ \\
\hline 10 & $35.1, \mathrm{C}$ & & & & \\
\hline \multirow[t]{2}{*}{11} & 27.3, $\mathrm{CH}_{2}$ & $1.52(a), t(13.2)$ & $8,9,10,2^{\prime}, 9^{\prime}$ & $\mathrm{H}-9$ & $\mathrm{H}-1 \mathrm{a}$ \\
\hline & & $1.45(\beta), m$ & & $\mathrm{H}-9$ & $\mathrm{H}-13, \mathrm{H}-1^{\prime} \mathrm{a}, \mathrm{H}-1^{\prime} \beta$ \\
\hline 12 & $27.2, \mathrm{CH}_{3}$ & $1.41, \mathrm{~s}$ & $7,8,9$ & & $\mathrm{H}-5, \mathrm{H}-7 \mathrm{a}, \mathrm{H}-1^{\prime} \mathrm{a}$ \\
\hline 13 & $21.9, \mathrm{CH}_{3}$ & $0.91, \mathrm{~s}$ & $1,5,9,10$ & & $\mathrm{H}-1 \beta, \mathrm{H}-9, \mathrm{H}-11 \beta$ \\
\hline 14 & $19.6, \mathrm{CH}_{3}$ & $1.07, \mathrm{~s}$ & $3,4,5,15$ & & \\
\hline 15 & $29.1, \mathrm{CH}_{3}$ & $1.09, \mathrm{~s}$ & $3,4,5,14$ & & $\mathrm{H}-2 \mathrm{a}, \mathrm{H}-5$ \\
\hline \multirow[t]{2}{*}{$1^{\prime}$} & $68.6, \mathrm{CH}_{2}$ & $4.14(\mathrm{a}),(\mathrm{dd}, 11.4,8.4)$ & $2^{\prime}, 7^{\prime}, 8^{\prime}$ & $\mathrm{H}-2^{\prime}$ & $\mathrm{H}-11 \beta, \mathrm{H}-12$ \\
\hline & & $4.52(\beta), t(8.4)$ & $2^{\prime}, 3^{\prime}$ & $\mathrm{H}-2^{\prime}$ & $\mathrm{H}-11 \beta, \mathrm{H}-2^{\prime}$ \\
\hline $2^{\prime}$ & $45.6, \mathrm{CH}$ & $3.00, \mathrm{dt}(11.4,7.7)$ & $1^{\prime}, 3^{\prime}, 4^{\prime}, 6^{\prime}, 7^{\prime}, 9^{\prime}$ & $\mathrm{H}-1^{\prime} \mathrm{a}, \mathrm{H}-1^{\prime} \beta, \mathrm{H}-7^{\prime}$ & $\mathrm{H}-1^{\prime} \beta, \mathrm{H}-7^{\prime}, \mathrm{H}-9^{\prime}$ \\
\hline $3^{\prime}$ & $35.8, \mathrm{C}$ & & & & \\
\hline $4^{\prime}$ & 177.6, C & & & & \\
\hline $5^{\prime}$ & $110.9, \mathrm{CH}$ & $5.65, \mathrm{~s}$ & $3^{\prime}, 4^{\prime}, 7^{\prime}$ & & \\
\hline $6^{\prime}$ & $185.5, \mathrm{C}$ & & & & \\
\hline $7^{\prime}$ & $49.1, \mathrm{CH}$ & $3.44, \mathrm{~d}(7.7)$ & $1^{\prime}, 2^{\prime}, 6^{\prime}, 8^{\prime}$ & $\mathrm{H}-2^{\prime}$ & $\mathrm{H}-2^{\prime}, \mathrm{H}-9^{\prime}$ \\
\hline $8^{\prime}$ & 170.7, C & & & & \\
\hline $9^{\prime}$ & $29.9, \mathrm{CH}_{3}$ & $1.47, \mathrm{~s}$ & $11,2^{\prime}, 3^{\prime}, 4^{\prime}$ & & $\mathrm{H}-9, \mathrm{H}-2^{\prime}, \mathrm{H}-7^{\prime}$ \\
\hline
\end{tabular}

${ }^{1} \mathrm{H}$ NMR: $600 \mathrm{MHz},{ }^{13} \mathrm{C}$ NMR: $150 \mathrm{MHz}\left(\right.$ in $\mathrm{CDCl}_{3}$ ) 
Table S8. NMR data for funiculolide C (3).

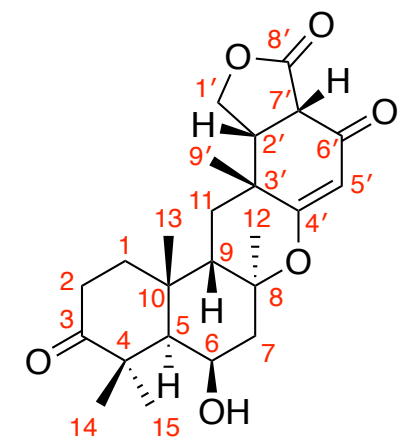

\begin{tabular}{|c|c|c|c|c|c|}
\hline position & $\delta_{c}$, type & $\delta_{\mathrm{H}}$, mult. $(J$ in $\mathrm{Hz})$ & HMBC correlation & COSY correlation & NOESY correlation \\
\hline \multirow[t]{2}{*}{1} & $30.7, \mathrm{CH}_{2}$ & $1.94(a)$, brt (12.1) & $2,3,5,13$ & $\mathrm{H}-2 \mathrm{a}, \mathrm{H}-2 \beta$ & $\mathrm{H}-5, \mathrm{H}-12$ \\
\hline & & $1.21(\beta)$, ddd $(12.8,9.9,5.5)$ & 5,10 & $\mathrm{H}-2 \mathrm{a}, \mathrm{H}-2 \beta$ & $\mathrm{H}-13$ \\
\hline \multirow[t]{2}{*}{2} & $32.9, \mathrm{CH}_{2}$ & $2.80(a)$, ddd $(15.8,12.1,5.5)$ & 1,3 & $\mathrm{H}-1 \mathrm{a}, \mathrm{H}-1 \beta$ & $\mathrm{H}-5, \mathrm{H}-15$ \\
\hline & & $2.12(\beta), m$ & $3,5,10$ & $\mathrm{H}-1 \mathrm{a}, \mathrm{H}-1 \beta$ & \\
\hline 3 & 217.8, C & & & & \\
\hline 4 & $46.6, \mathrm{C}$ & & & & \\
\hline 5 & $48.0, \mathrm{CH}$ & 1.75, brs & $1,4,6,10,13,14,15$ & $\mathrm{H}-6$ & $\mathrm{H}-1 \mathrm{a}, \mathrm{H}-2 \mathrm{a}, \mathrm{H}-6, \mathrm{H}-7 \mathrm{a}, \mathrm{H}-12, \mathrm{H}-15$ \\
\hline 6 & $64.4, \mathrm{CH}$ & $4.18, t(4.4)$ & $4,5,8,10$ & $\mathrm{H}-5, \mathrm{H}-7 \mathrm{a}, 6-\mathrm{OH}$ & $\mathrm{H}-5, \mathrm{H}-7 \mathrm{a}, \mathrm{H}-14, \mathrm{H}-15,6-\mathrm{OH}$ \\
\hline \multirow[t]{2}{*}{7} & $49.1, \mathrm{CH}_{2}$ & $2.11(a), m$ & $6,9,12$ & $\mathrm{H}-6$ & $\mathrm{H}-5, \mathrm{H}-6, \mathrm{H}-12$ \\
\hline & & $2.06(\beta), d(14.9)$ & $5,6,8,12$ & & $6-\mathrm{OH}$ \\
\hline 8 & $83.9, \mathrm{C}$ & & & & \\
\hline 9 & $39.9, \mathrm{CH}$ & $2.83 \mathrm{dd}(13.2,2.6)$ & $1,8,10,12$ & $\mathrm{H}-11 \alpha, \mathrm{H}-11 \beta$ & $\mathrm{H}-13, \mathrm{H}-9^{\prime}$ \\
\hline 10 & $34.6, \mathrm{C}$ & & & & \\
\hline \multirow[t]{2}{*}{11} & $26.1, \mathrm{CH}_{2}$ & $1.45(a), t(13.6)$ & $8,9,2^{\prime}, 3^{\prime}, 9^{\prime}$ & $\mathrm{H}-9$ & \\
\hline & & $1.53(\beta), \mathrm{dd}(13.6,2.6)$ & $8,9,3^{\prime}, 4^{\prime}, 9^{\prime}$ & $\mathrm{H}-9$ & $\mathrm{H}-13$ \\
\hline 12 & $26.2, \mathrm{CH}_{3}$ & $1.35, \mathrm{~s}$ & $7,8,9$ & & $\mathrm{H}-1 \mathrm{a}, \mathrm{H}-5, \mathrm{H}-7 \mathrm{a}, \mathrm{H}-1^{\prime} \mathrm{a}$ \\
\hline 13 & $23.8, \mathrm{CH}_{3}$ & $1.05, \mathrm{~s}$ & $1,5,9,10$ & & $\mathrm{H}-1 \beta, \mathrm{H}-9, \mathrm{H}-11 \beta$ \\
\hline 14 & $21.7, \mathrm{CH}_{3}$ & $1.17, \mathrm{~s}$ & $3,4,5,15$ & & $\mathrm{H}-6,6-\mathrm{OH}$ \\
\hline 15 & $28.8, \mathrm{CH}_{3}$ & $1.04, \mathrm{~s}$ & $3,4,5,14$ & & $\mathrm{H}-2 \mathrm{a}, \mathrm{H}-5, \mathrm{H}-6$ \\
\hline \multirow[t]{2}{*}{$1^{\prime}$} & $68.7, \mathrm{CH}_{2}$ & $4.04(a)$, dd $(11,4,8.8)$ & $2^{\prime}, 3^{\prime}$ & $\mathrm{H}-2^{\prime}$ & $\mathrm{H}-12$ \\
\hline & & $4.58(\beta), t(8.4)$ & $2^{\prime}, 7^{\prime}, 8^{\prime}$ & $\mathrm{H}-2^{\prime}$ & \\
\hline $2^{\prime}$ & $44.5, \mathrm{CH}$ & $3.10, \mathrm{dt}(11.4,7.7)$ & $1^{\prime}, 3^{\prime}, 4^{\prime}, 6^{\prime}, 7^{\prime}, 9^{\prime}$ & $\mathrm{H}-1^{\prime} \mathrm{a}, \mathrm{H}-1^{\prime} \beta, \mathrm{H}-7^{\prime}$ & $\mathrm{H}-7^{\prime}, \mathrm{H}-9^{\prime}$ \\
\hline $3^{\prime}$ & $35.5, \mathrm{C}$ & & & & \\
\hline $4^{\prime}$ & $179.1, \mathrm{C}$ & & & & \\
\hline $5^{\prime}$ & 109.2, $\mathrm{CH}$ & $5.41, \mathrm{~s}$ & $3^{\prime}, 4^{\prime}, 7^{\prime}$ & & \\
\hline $6^{\prime}$ & $186.2, \mathrm{C}$ & & & & \\
\hline $7^{\prime}$ & $48.8, \mathrm{CH}$ & $3.65, \mathrm{~d}(7.7)$ & $1^{\prime}, 2^{\prime}, 6^{\prime}, 8^{\prime}$ & $\mathrm{H}-2^{\prime}$ & $\mathrm{H}-2^{\prime}, \mathrm{H}-9^{\prime}$ \\
\hline $8^{\prime}$ & $171.2, \mathrm{C}$ & & & & \\
\hline $9^{\prime}$ & $29.2, \mathrm{CH}_{3}$ & $1.39, \mathrm{~s}$ & $11,2^{\prime}, 3^{\prime}, 4^{\prime}$ & & $\mathrm{H}-9, \mathrm{H}-2^{\prime}, \mathrm{H}-7^{\prime}$ \\
\hline $6-\mathrm{OH}$ & & $4.79, \mathrm{~d}(3.3)$ & 5,6 & $\mathrm{H}-6$ & $\mathrm{H}-6, \mathrm{H}-7 \beta, \mathrm{H}-14$ \\
\hline
\end{tabular}

${ }^{1} \mathrm{H}$ NMR: $600 \mathrm{MHz},{ }^{13} \mathrm{C}$ NMR: $150 \mathrm{MHz}$ (in DMSO- $d_{6}$ ) 
Table S9. NMR data for funiculolide D (4).

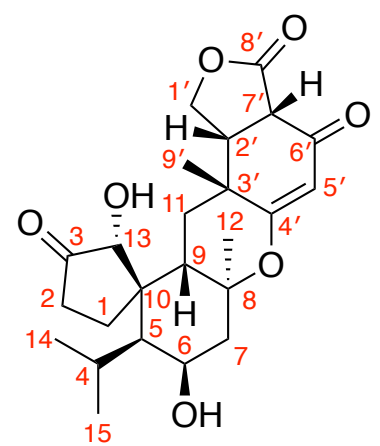

\begin{tabular}{|c|c|c|c|c|c|}
\hline position & $\delta_{c}$, type & $\delta_{\mathrm{H}}$, mult. $(\mathrm{J}$ in $\mathrm{Hz})$ & HMBC correlation & COSY correlation & NOESY correlation \\
\hline \multirow[t]{2}{*}{1} & $24.8, \mathrm{CH}_{2}$ & $2.16(a), m$ & & $\mathrm{H}-2 \mathrm{a}, \mathrm{H}-2 \beta$ & \\
\hline & & $1.92(\beta), m$ & & $\mathrm{H}-2 \mathrm{a}, \mathrm{H}-2 \beta$ & $\mathrm{H}-2 \beta, \mathrm{H}-13$ \\
\hline \multirow[t]{2}{*}{2} & $33.8, \mathrm{CH}_{2}$ & $2.19(a), m$ & $1,3,13$ & $\mathrm{H}-1 \alpha, \mathrm{H}-1 \beta$ & \\
\hline & & $2.48(\beta), m$ & & $\mathrm{H}-1 \alpha, \mathrm{H}-1 \beta$ & $\mathrm{H}-1 \beta, \mathrm{H}-13$ \\
\hline 3 & 218.0, C & & & & \\
\hline 4 & $27.2, \mathrm{CH}$ & $2.17, \mathrm{~m}$ & & $\mathrm{H}-14, \mathrm{H}-15$ & $\mathrm{H}-13, \mathrm{H}-14, \mathrm{H}-15$ \\
\hline 5 & $51.5, \mathrm{CH}$ & 1.50, brs & $1,10,13,15$ & & $\mathrm{H}-6, \mathrm{H}-15$ \\
\hline 6 & $65.6, \mathrm{CH}$ & $4.23, \mathrm{~m}$ & & $\mathrm{H}-7$ & $\mathrm{H}-5, \mathrm{H}-14, \mathrm{H}-15$ \\
\hline 7 & $49.9, \mathrm{CH}_{2}$ & $2.13, \mathrm{~m}$ & $5,6,8$ & $\mathrm{H}-6$ & \\
\hline 8 & $84.7, \mathrm{C}$ & & & & \\
\hline 9 & $33.7, \mathrm{CH}$ & 3.40, brd (12.1) & & $\mathrm{H}-11 \alpha, \mathrm{H}-11 \beta$ & $\mathrm{H}-11 \beta, \mathrm{H}-9^{\prime}$ \\
\hline 10 & $48.7, \mathrm{C}$ & & & & \\
\hline \multirow[t]{2}{*}{11} & $30.4, \mathrm{CH}_{2}$ & $1.63(a), t(12.8)$ & $9^{\prime}$ & $\mathrm{H}-9$ & $H-12, H-1^{\prime} a, H-1^{\prime} \beta$ \\
\hline & & $1.14(\beta), \operatorname{brd}(12.8)$ & $8,4^{\prime}$ & $\mathrm{H}-9$ & $\mathrm{H}-9, \mathrm{H}-2^{\prime}, \mathrm{H}-9^{\prime}$ \\
\hline 12 & $26.8, \mathrm{CH}_{3}$ & $1.39, \mathrm{~s}$ & $7,8,9$ & & $H-11 a, H-1^{\prime} a$ \\
\hline 13 & $77.5, \mathrm{CH}$ & $4.24, \mathrm{~s}$ & $2,3,5,10$ & & $\mathrm{H}-1 \beta, \mathrm{H}-2 \beta, \mathrm{H}-4, \mathrm{H}-14$ \\
\hline 14 & $20.1, \mathrm{CH}_{3}$ & $1.06, d(5.1)$ & $4,5,15$ & $\mathrm{H}-4$ & $\mathrm{H}-4, \mathrm{H}-6, \mathrm{H}-13$ \\
\hline 15 & $25.7, \mathrm{CH}_{3}$ & $1.08, d(5.5)$ & $4,5,14$ & $\mathrm{H}-4$ & $\mathrm{H}-4, \mathrm{H}-5, \mathrm{H}-6$ \\
\hline \multirow[t]{2}{*}{$1^{\prime}$} & $70.7, \mathrm{CH}_{2}$ & $4.14(a)$, dd $(11.4,8.8)$ & $2^{\prime}, 3^{\prime}$ & $\mathrm{H}-2^{\prime}$ & $\mathrm{H}-11 \mathrm{a}, \mathrm{H}-12$ \\
\hline & & $4.64(\beta), t(8.8)$ & $2^{\prime}, 7^{\prime}, 8^{\prime}$ & $\mathrm{H}-2^{\prime}$ & $\mathrm{H}-11 \mathrm{a}, \mathrm{H}-2^{\prime}$ \\
\hline $2^{\prime}$ & $46.2, \mathrm{CH}$ & 3.07, dt $(11.4,8.1)$ & $1^{\prime}, 3^{\prime}, 4^{\prime}, 6^{\prime}, 7^{\prime}, 9^{\prime}$ & $\mathrm{H}-1^{\prime} \mathrm{a}, \mathrm{H}-1^{\prime} \beta, \mathrm{H}-7^{\prime}$ & $\mathrm{H}-11 \beta, \mathrm{H}-1^{\prime} \beta, \mathrm{H}-9^{\prime}$ \\
\hline $3^{\prime}$ & 37.3, C & & & & \\
\hline $4^{\prime}$ & $181.5, \mathrm{C}$ & & & & \\
\hline $5^{\prime}$ & $110.3, \mathrm{CH}$ & $5.52, \mathrm{~s}$ & $3^{\prime}, 4^{\prime}, 7^{\prime}$ & & \\
\hline $6^{\prime}$ & $188.9, \mathrm{C}$ & & & & \\
\hline $7^{\prime}$ & $50.0, \mathrm{CH}$ & $3.55, \mathrm{~d}(7.7)$ & $6^{\prime}, 8^{\prime}$ & $\mathrm{H}-2^{\prime}$ & \\
\hline $8^{\prime}$ & 173.6, C & & & & \\
\hline $9^{\prime}$ & $30.7, \mathrm{CH}_{3}$ & $1.46, \mathrm{~s}$ & $11,2^{\prime}, 3^{\prime}, 4^{\prime}$ & & $\mathrm{H}-9, \mathrm{H}-11 \beta, \mathrm{H}-2^{\prime}$ \\
\hline
\end{tabular}

${ }^{1} \mathrm{H}$ NMR: $600 \mathrm{MHz},{ }^{13} \mathrm{C}$ NMR: $150 \mathrm{MHz}$ (in $\mathrm{CD}_{3} \mathrm{OD}$ )

Note: The ${ }^{1} \mathrm{H}$ signal of $\mathrm{H}-\mathrm{7}^{\prime}$ gradually exchanged with deuterium of the solvent. 


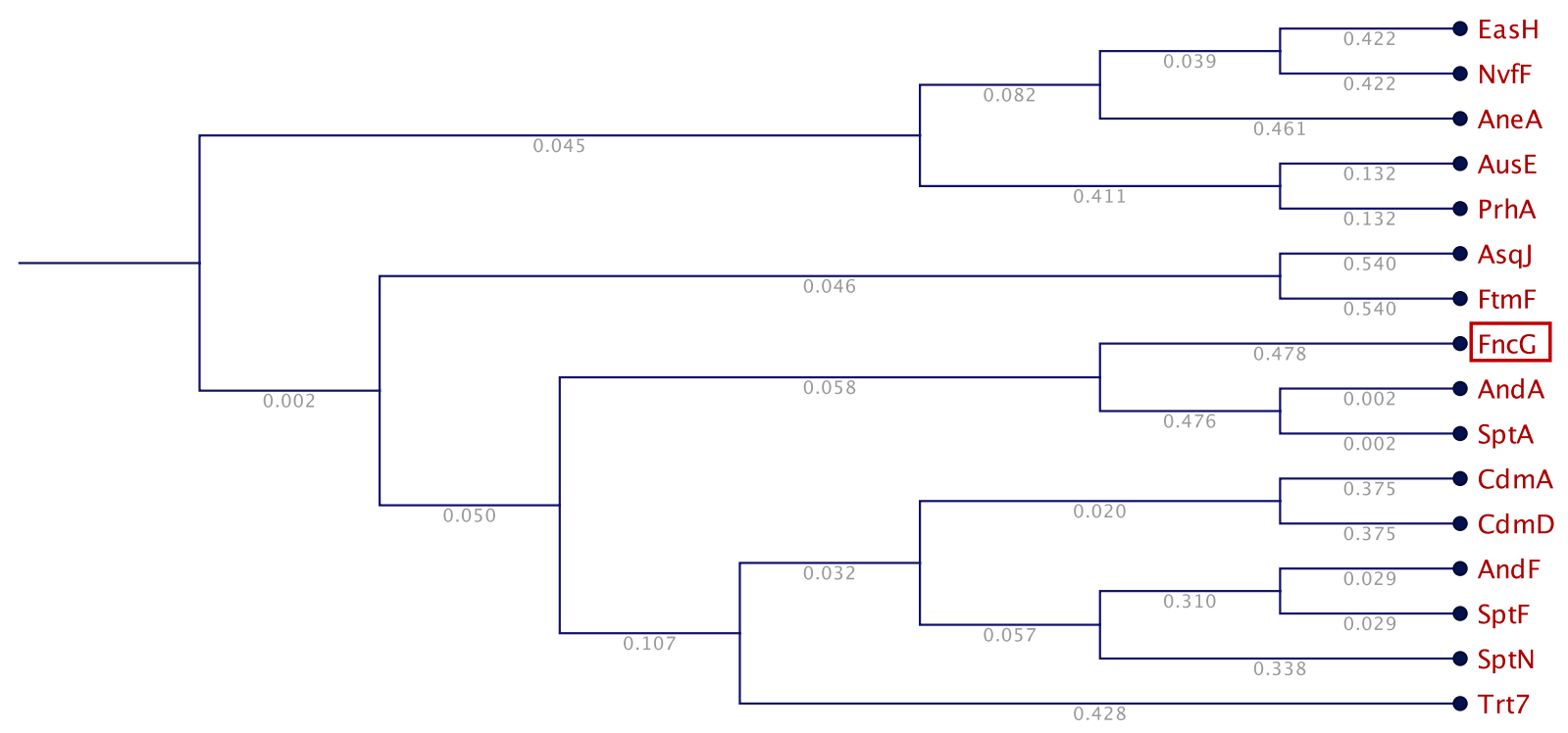

Figure S1. Phylogenetic analysis of FncG and its homologues involved in fungal natural product pathways. The phylogenetic tree was drawn using CLC Main Workbench 21.0.3 (QIAGEN) with the Kimura protein distance analysis (UPGMA algorithm).

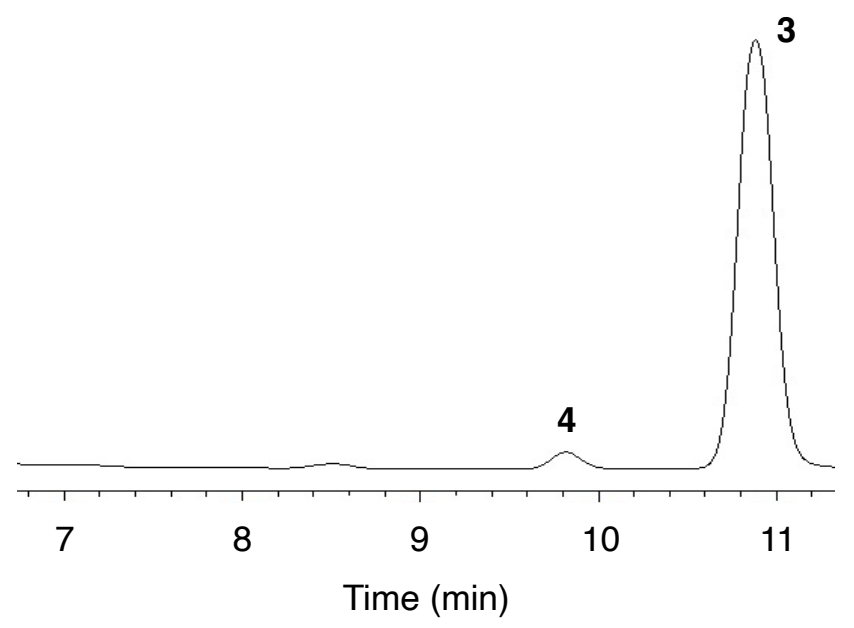

Figure S2. HPLC analysis of the fractions containing 3 after flash chromatography. The chromatogram revealed the presence of a minor product 4 . The chromatogram was monitored at $280 \mathrm{~nm}$. 


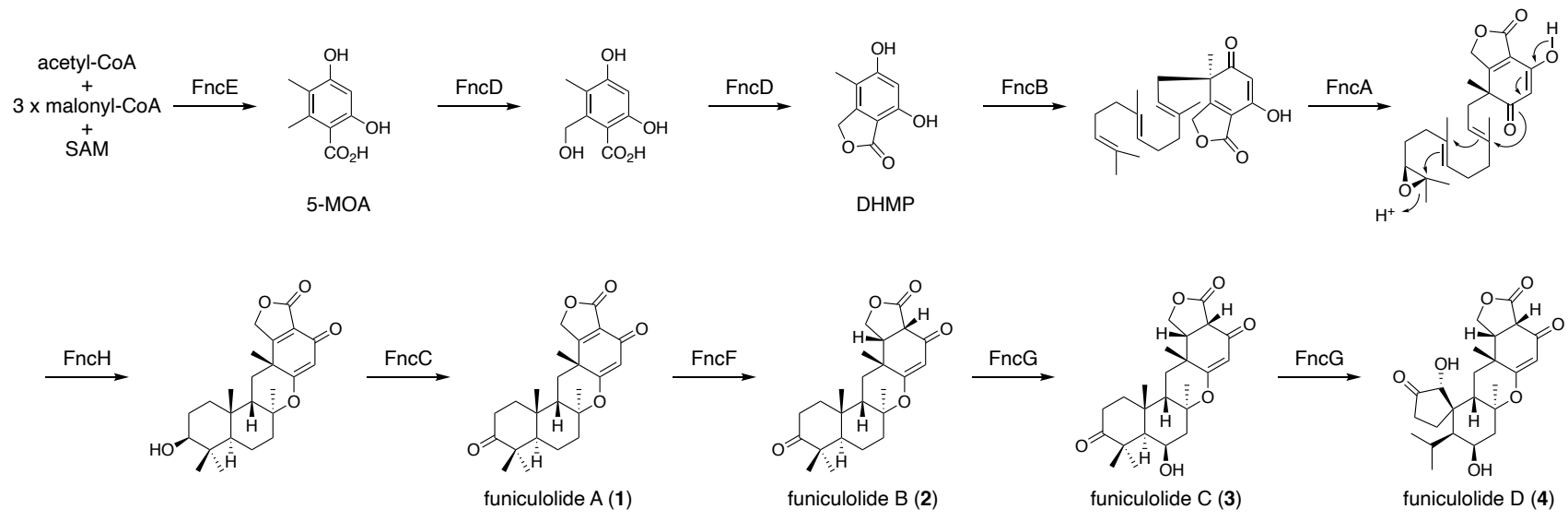

Figure S3. Proposed complete biosynthetic pathway of funiculolides.

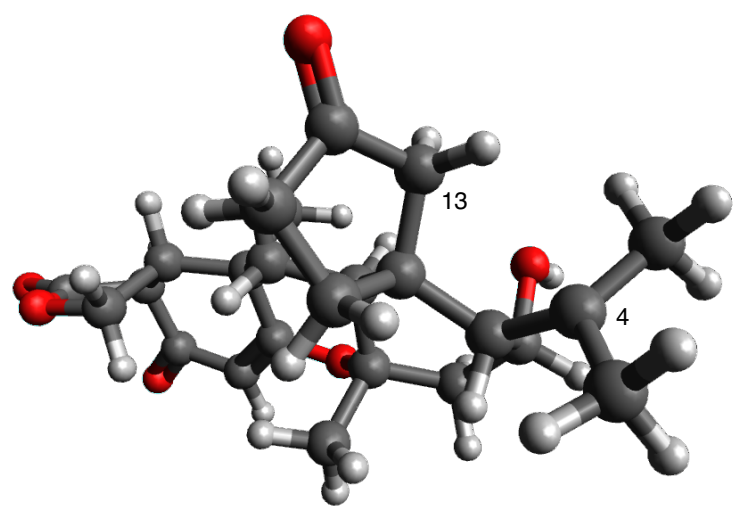

Figure S4. Modeled structure of 3c.

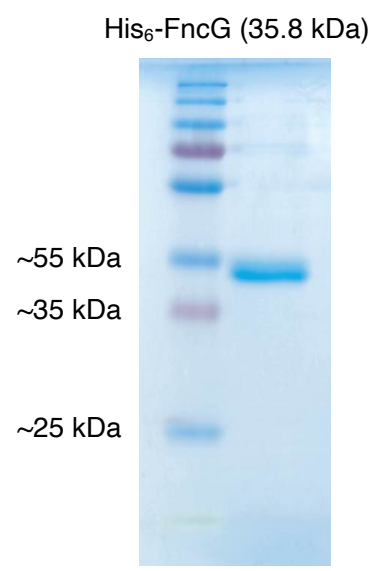

Figure S5. SDS-PAGE analysis of the purified protein. 


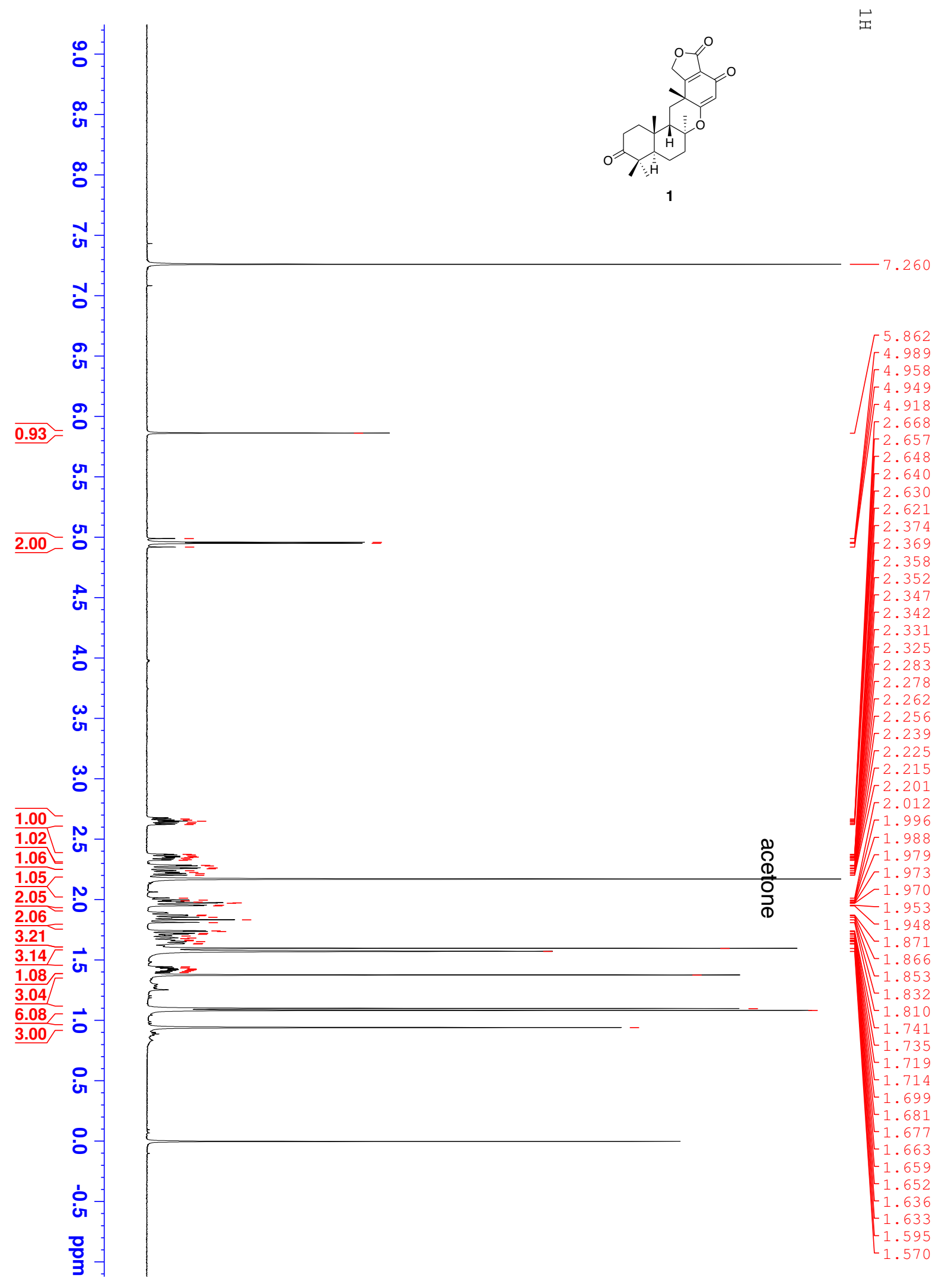

Figure S6. ${ }^{1} \mathrm{H}$ NMR spectrum of funiculolide $\mathrm{A}(\mathbf{1})$ in $\mathrm{CDCl}_{3}$ at $600 \mathrm{MHz}$. 


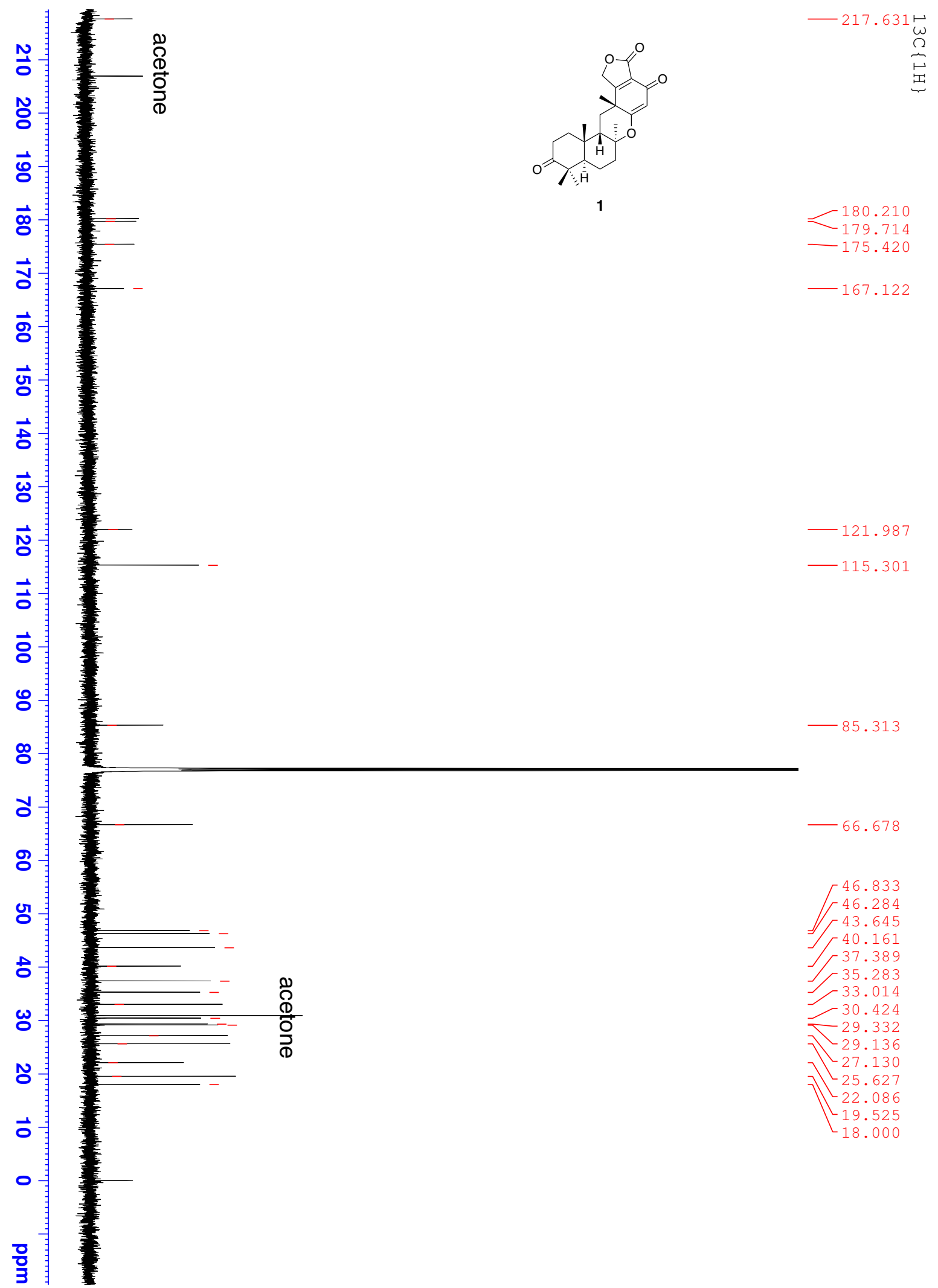

Figure S7. ${ }^{13} \mathrm{C}$ NMR spectrum of funiculolide $\mathrm{A}(\mathbf{1})$ in $\mathrm{CDCl}_{3}$ at $150 \mathrm{MHz}$. 


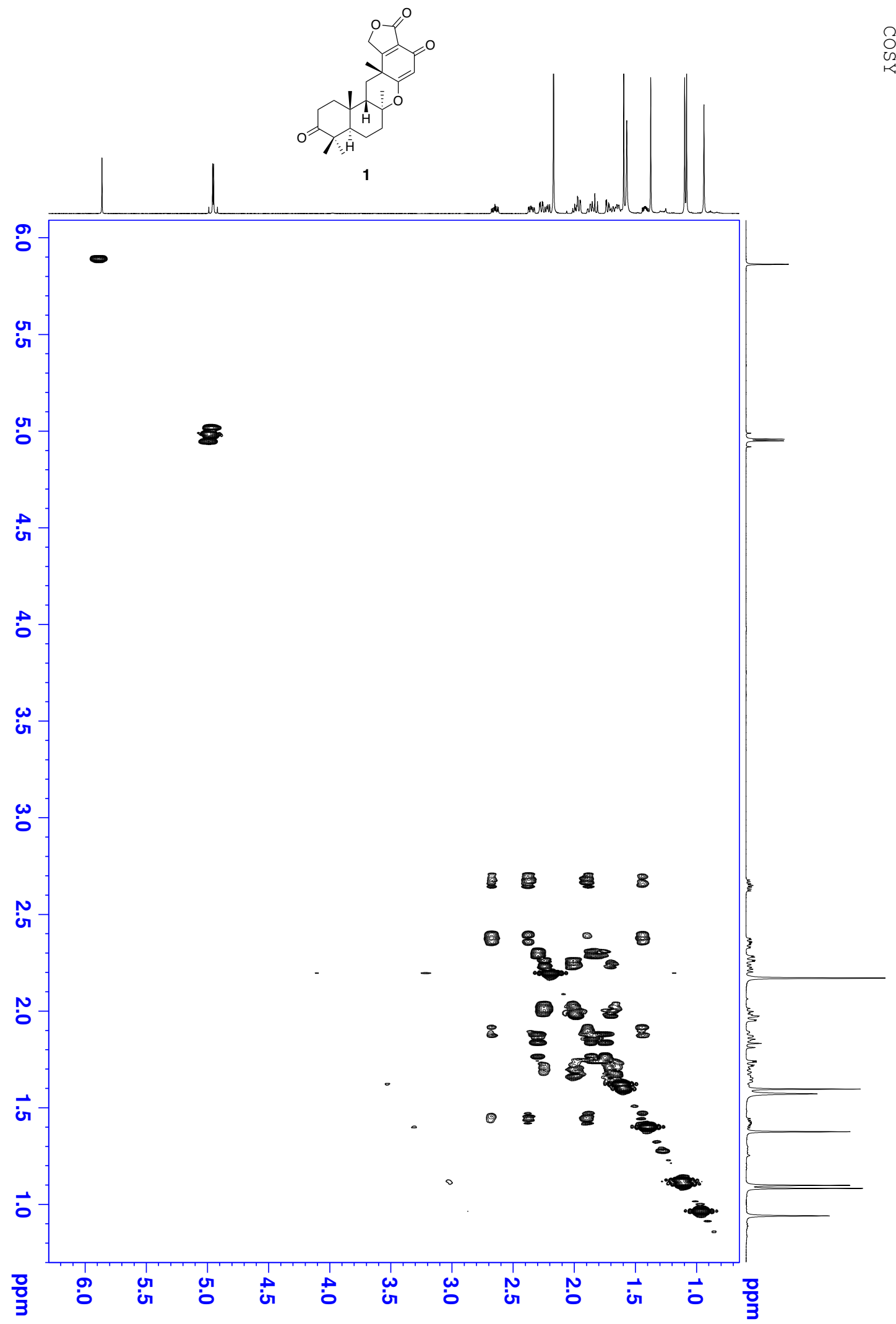

Figure S8. ${ }^{1} \mathrm{H}-{ }^{1} \mathrm{H}$ COSY spectrum of funiculolide $\mathrm{A}(\mathbf{1})$ in $\mathrm{CDCl}_{3}$. 


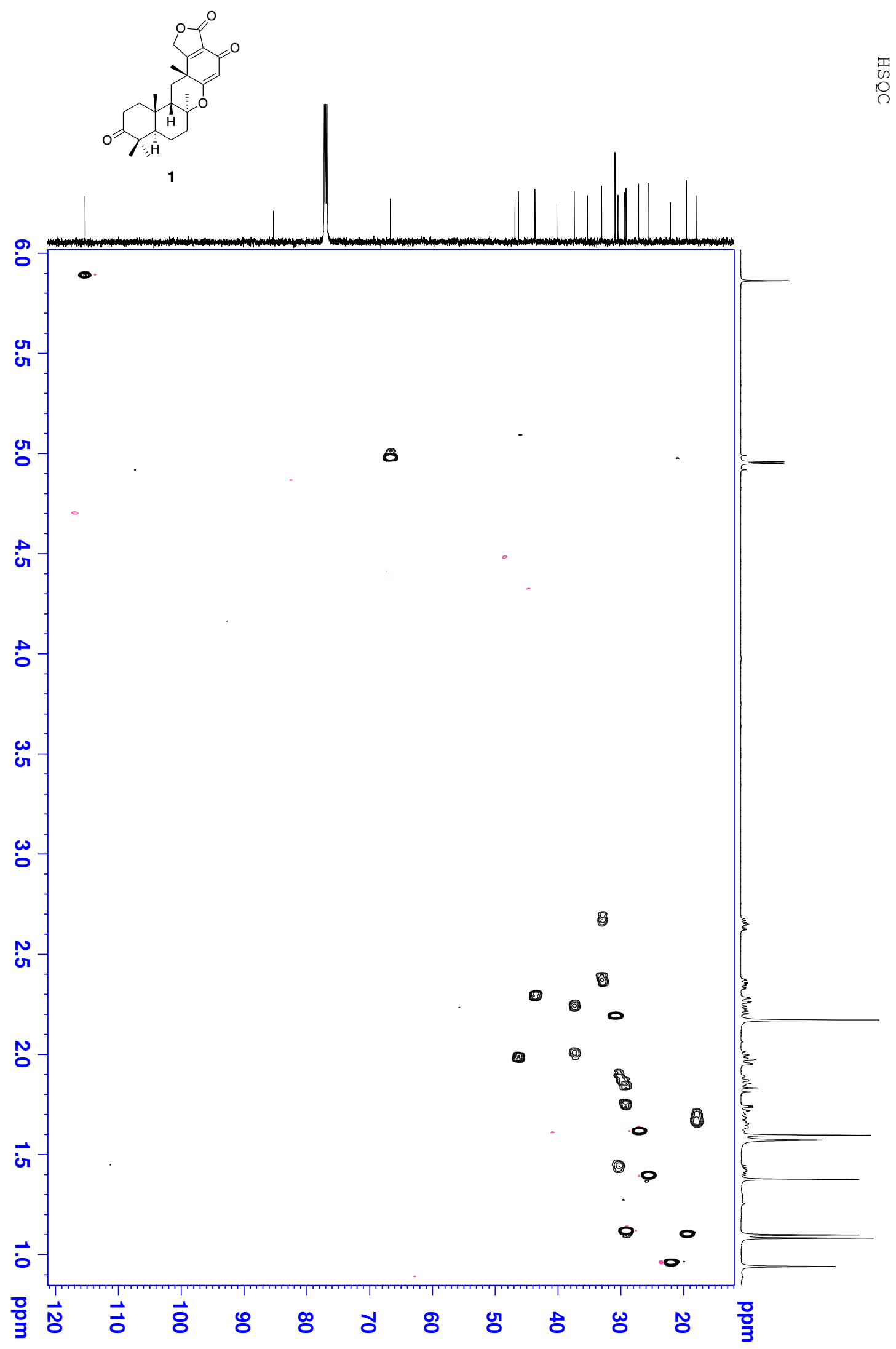

Figure S9. HSQC spectrum of funiculolide $\mathrm{A}(\mathbf{1})$ in $\mathrm{CDCl}_{3}$. 


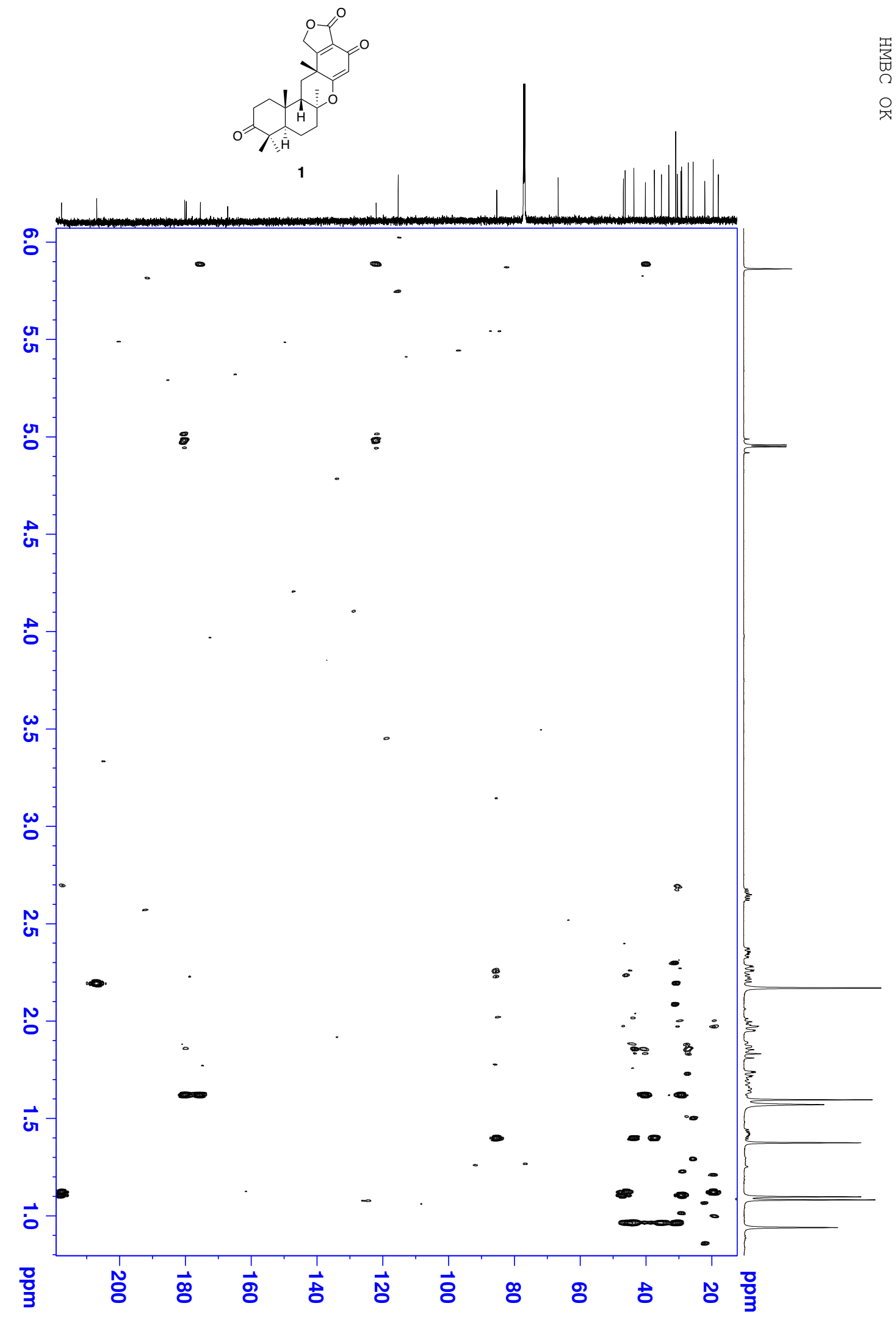

Figure S10. HMBC of funiculolide A (1) in $\mathrm{CDCl}_{3}$. 


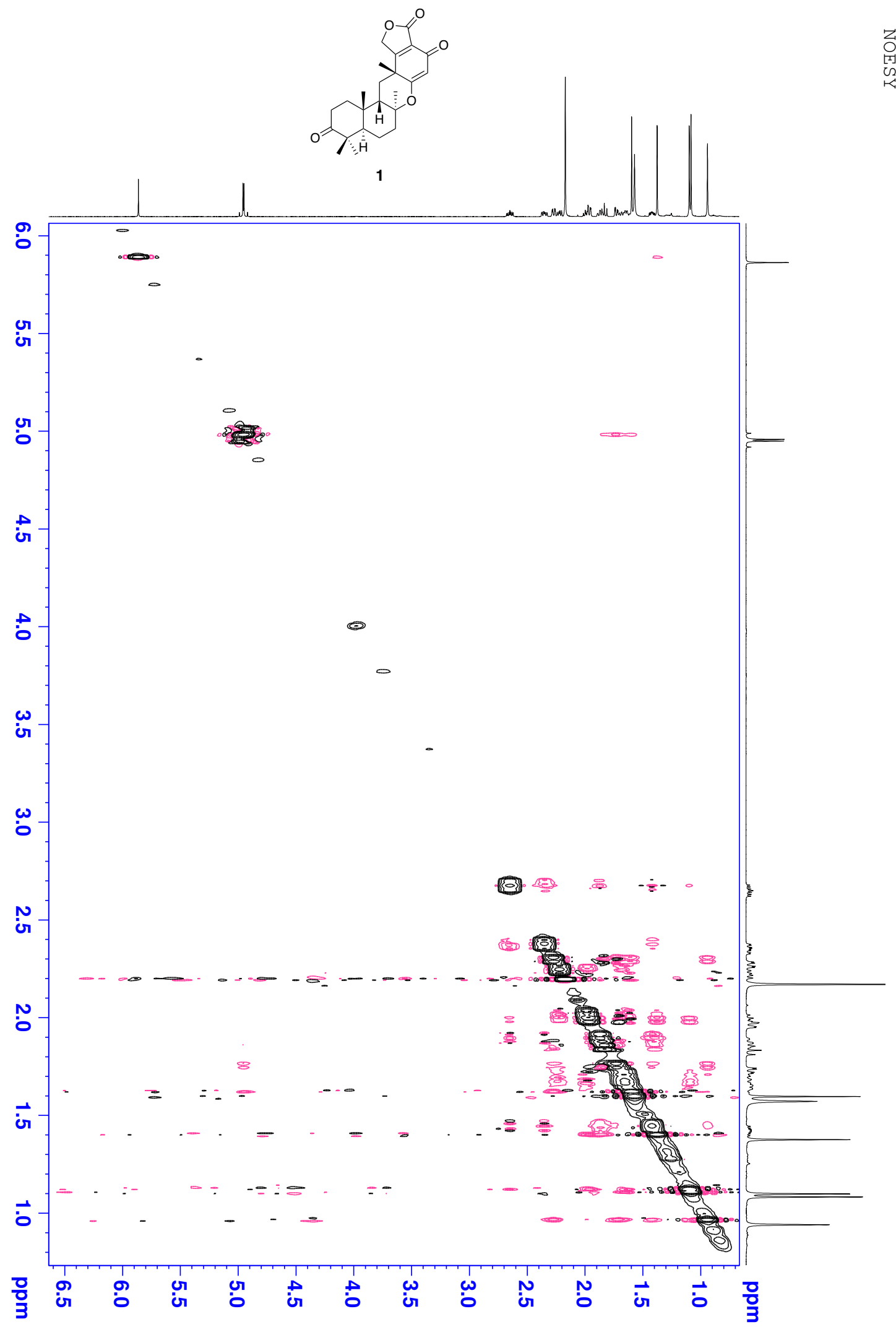

Figure S11. NOESY spectrum of funiculolide $\mathrm{A}(\mathbf{1})$ in $\mathrm{CDCl}_{3}$. 


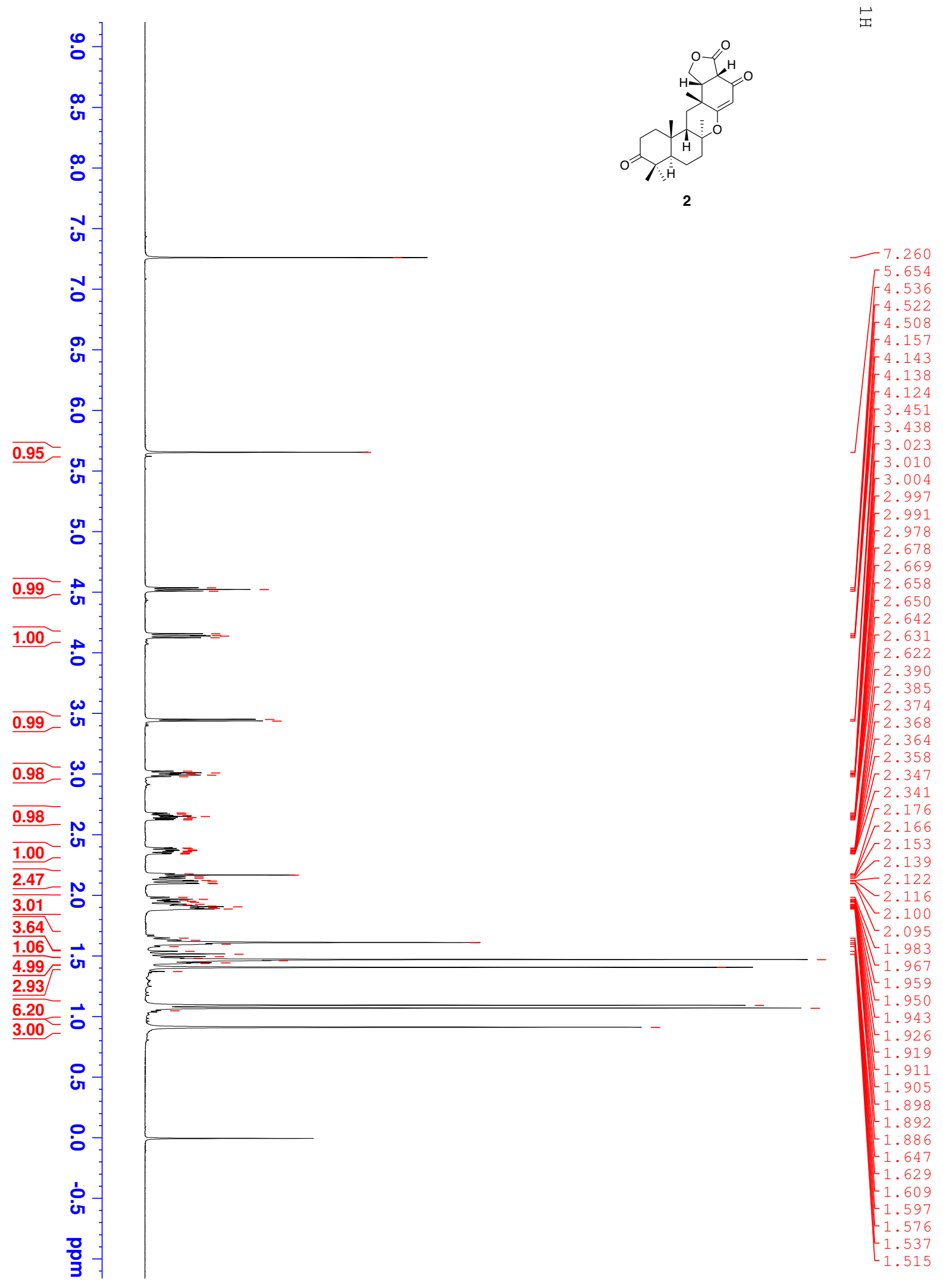

Figure S12. ${ }^{1} \mathrm{H}$ NMR spectrum of funiculolide $\mathrm{B}(2)$ in $\mathrm{CDCl}_{3}$ at $600 \mathrm{MHz}$. 


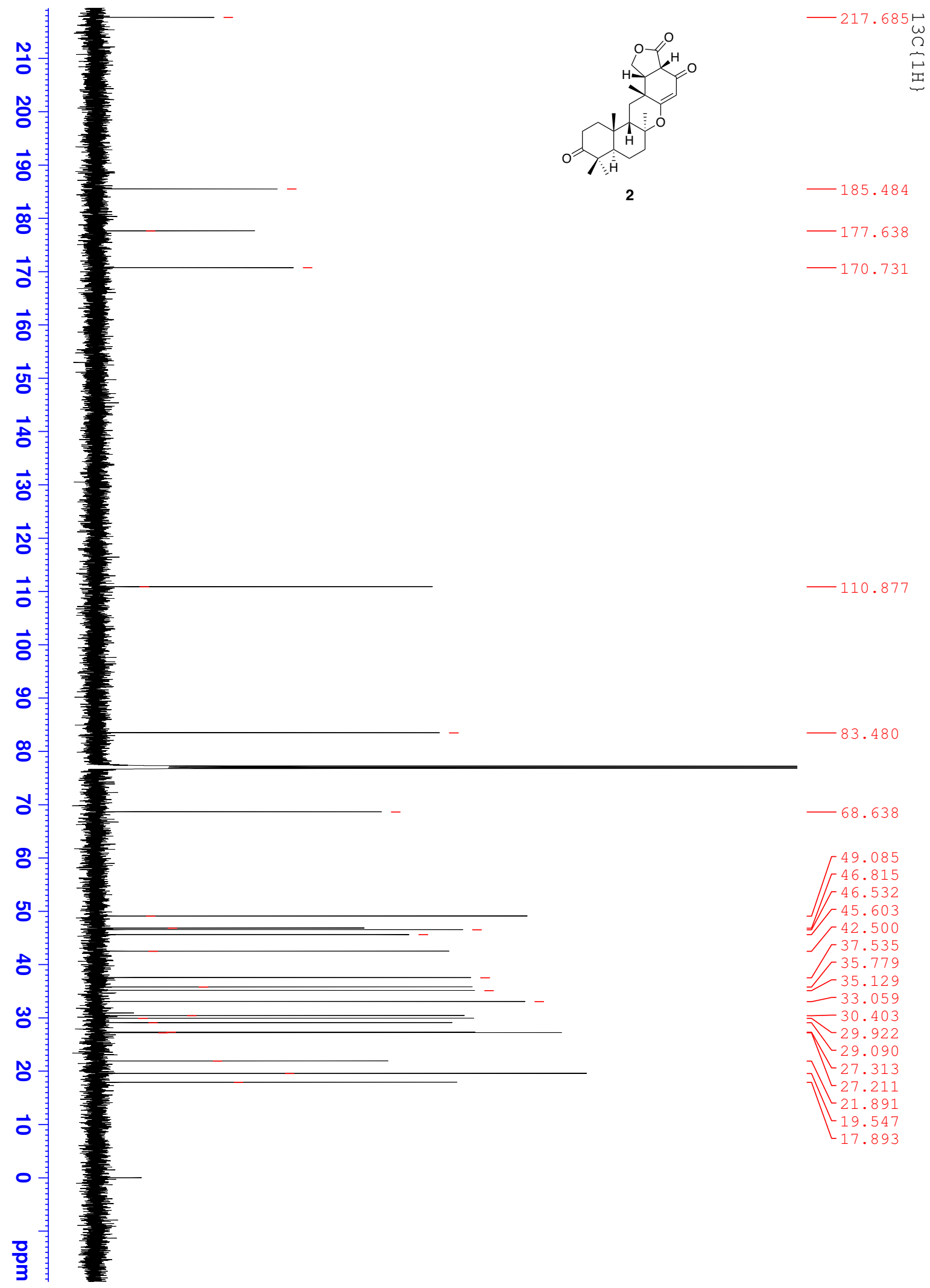

Figure S13. ${ }^{13} \mathrm{C}$ NMR spectrum of funiculolide $\mathrm{B}(2)$ in $\mathrm{CDCl}_{3}$ at $150 \mathrm{MHz}$. 


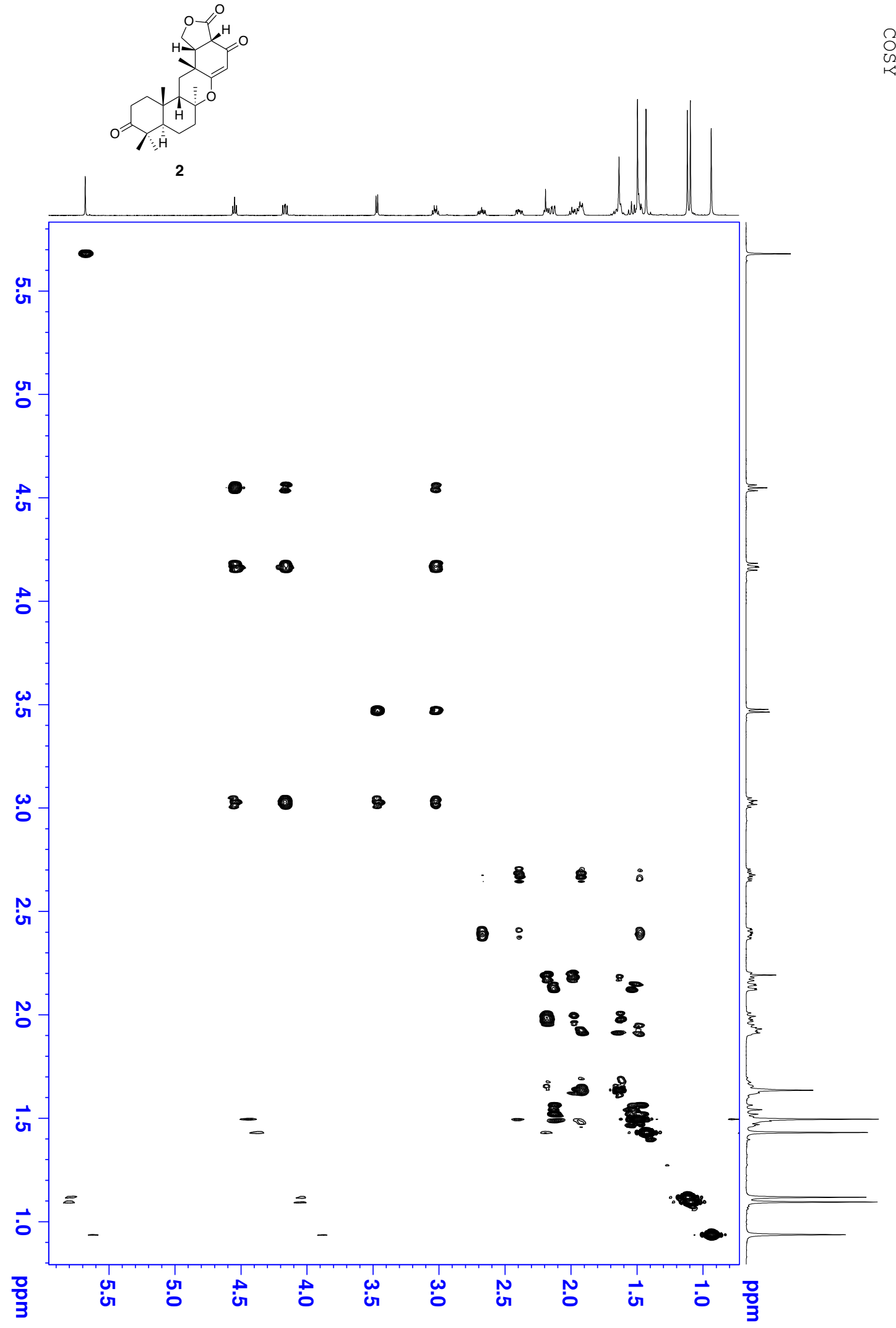

Figure S14. ${ }^{1} \mathrm{H}-{ }^{1} \mathrm{H}$ COSY spectrum of funiculolide B (2) in $\mathrm{CDCl}_{3}$. 


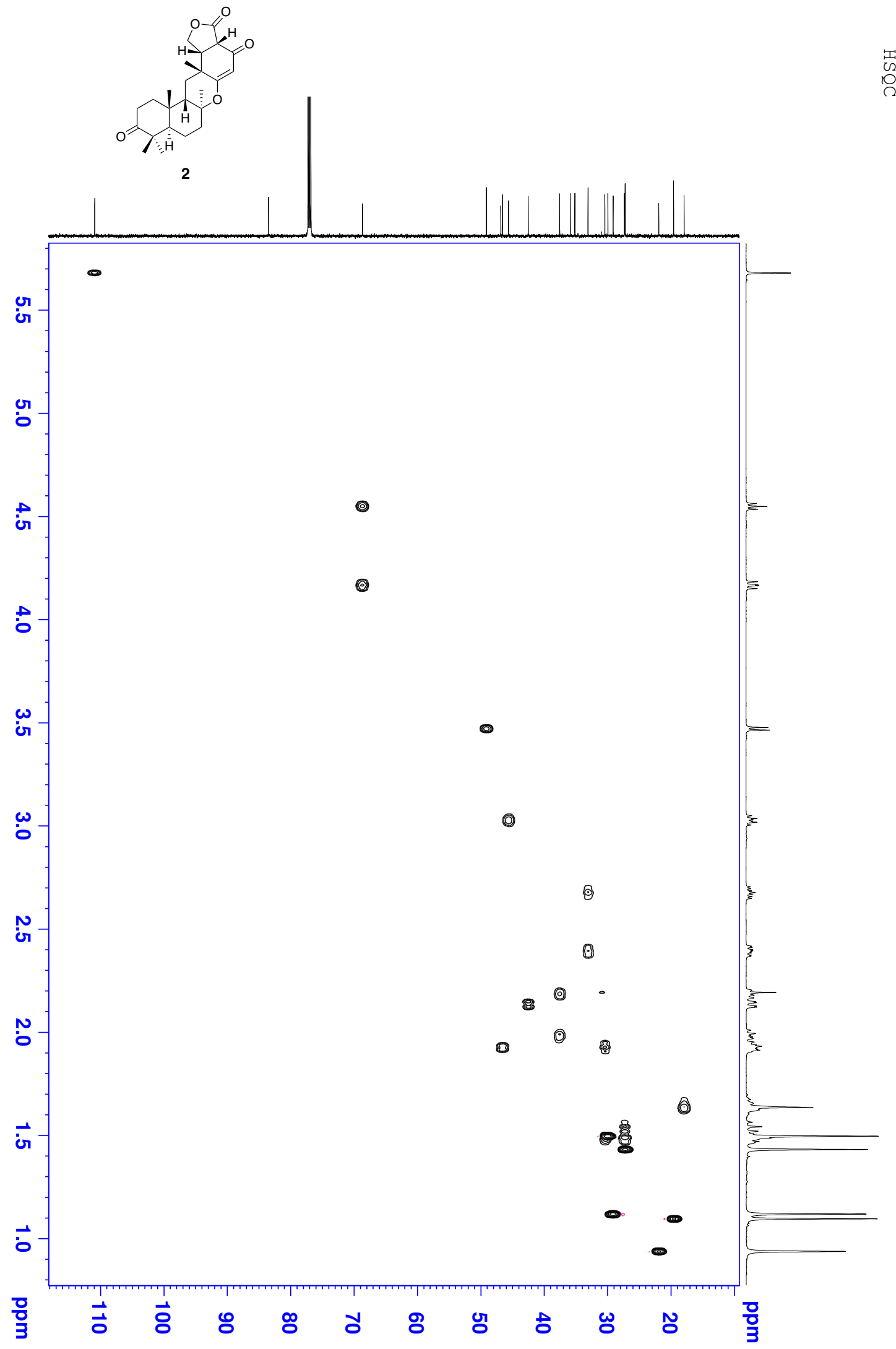

Figure S15. HSQC spectrum of funiculolide $\mathrm{B}(2)$ in $\mathrm{CDCl}_{3}$. 


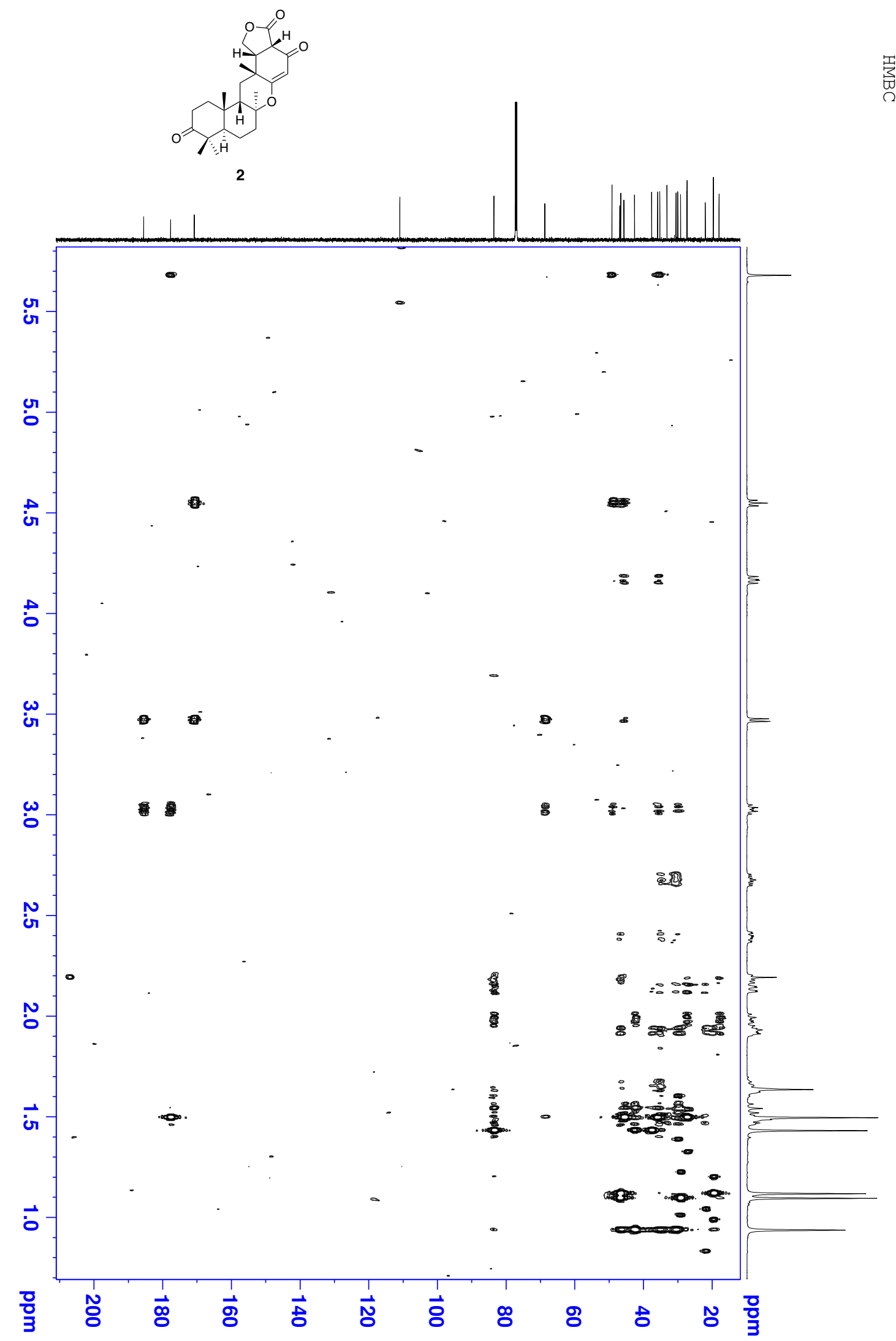

Figure S16. HMBC of funiculolide B (2) in $\mathrm{CDCl}_{3}$. 

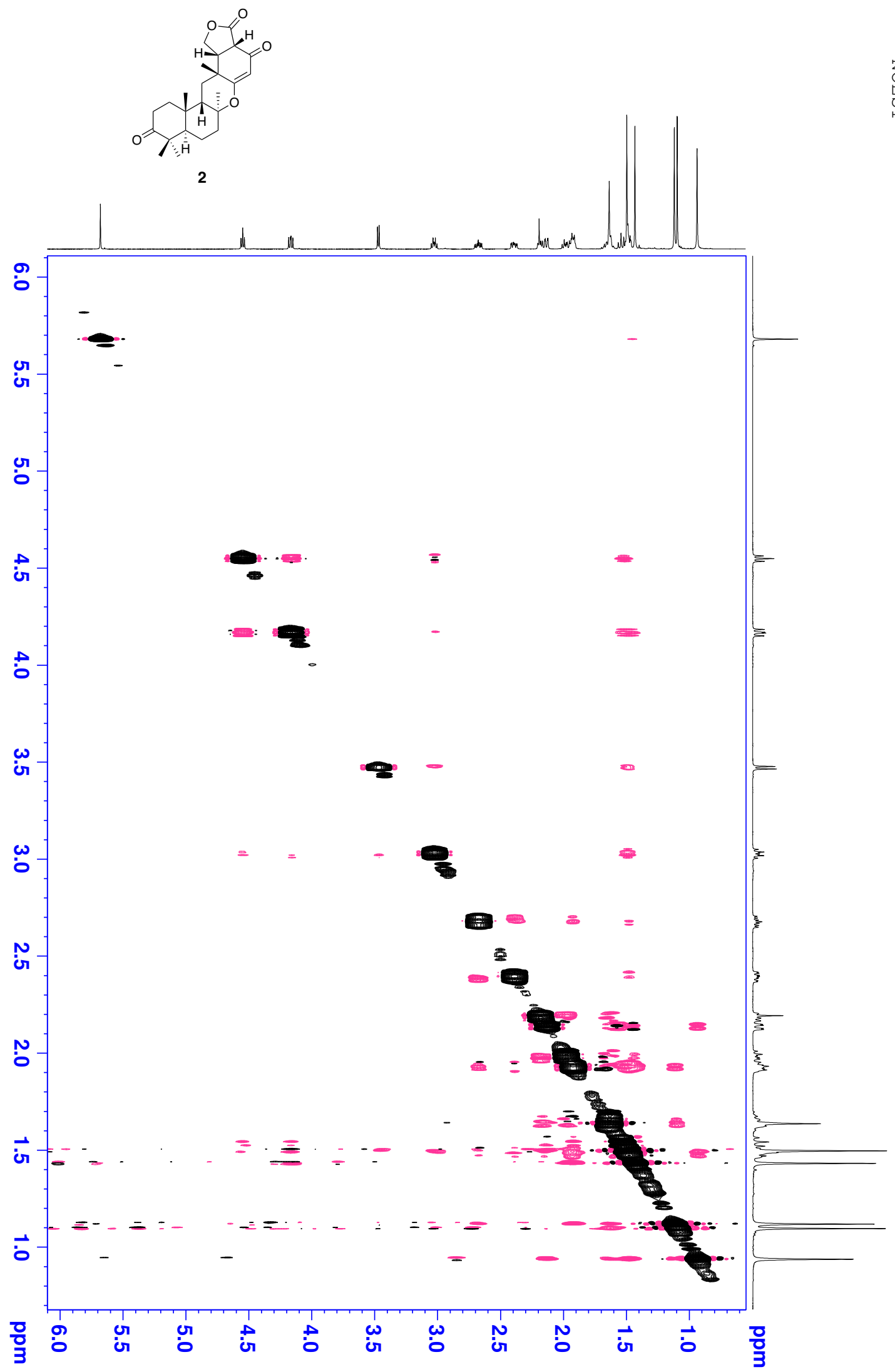

Figure S17. NOESY spectrum of funiculolide B (2) in $\mathrm{CDCl}_{3}$. 


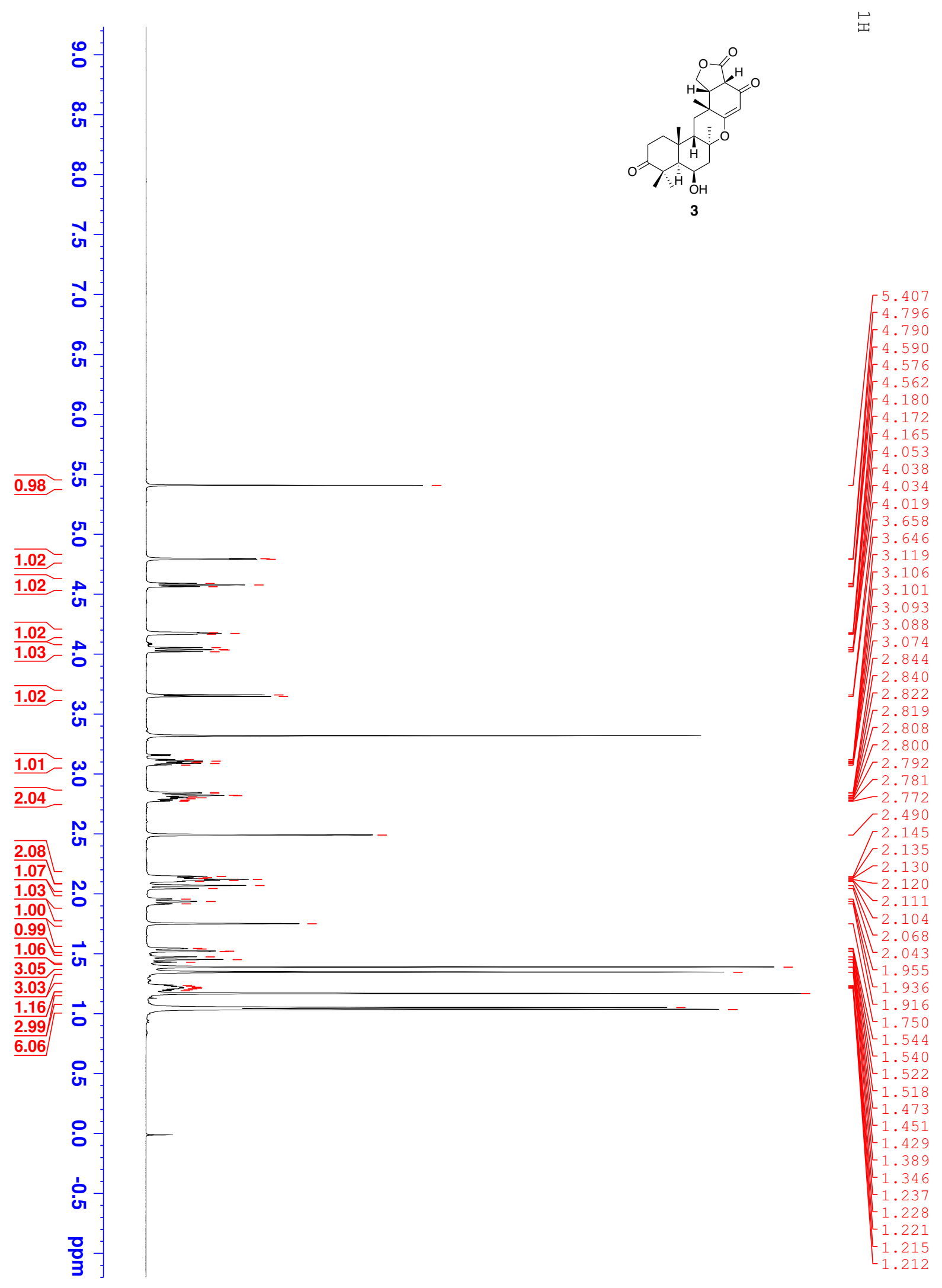

Figure S18. ${ }^{1} \mathrm{H}$ NMR spectrum of funiculolide C (3) in DMSO- $d_{6}$ at $600 \mathrm{MHz}$. 


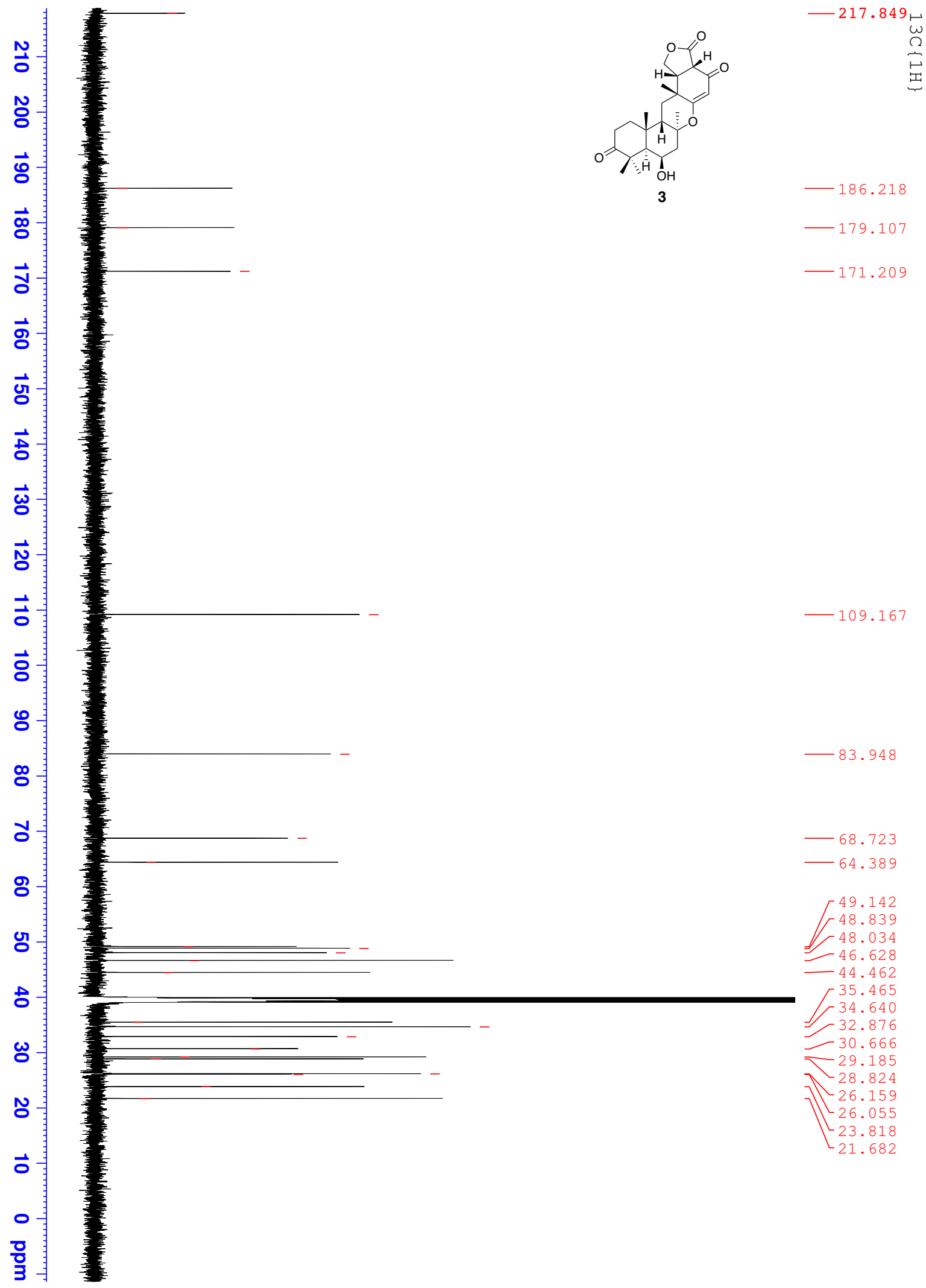

Figure S19. ${ }^{13} \mathrm{C}$ NMR spectrum of funiculolide C (3) in DMSO- $d_{6}$ at $150 \mathrm{MHz}$. 


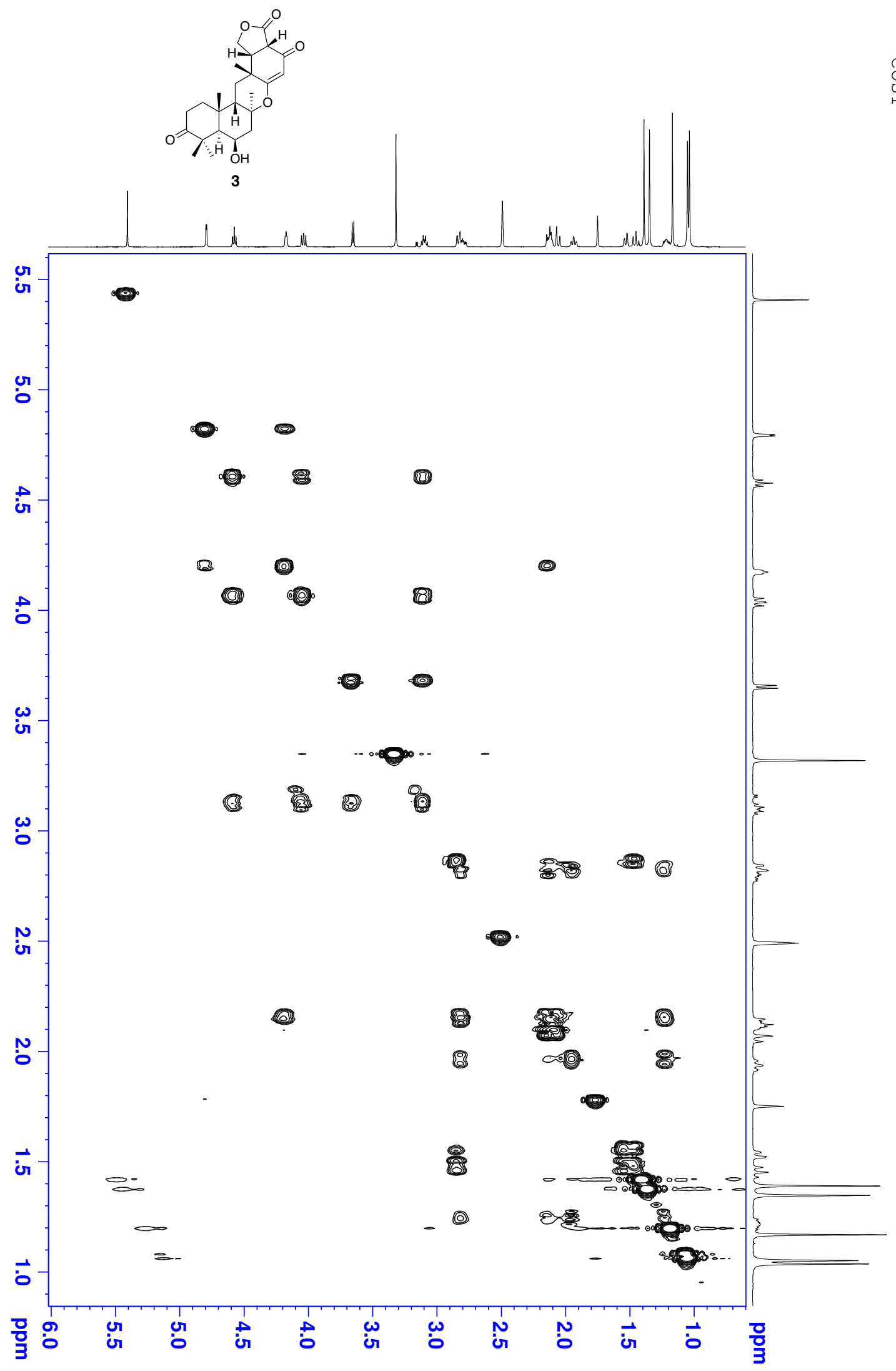

Figure S20. ${ }^{1} \mathrm{H}-{ }^{1} \mathrm{H}$ COSY spectrum of funiculolide C (3) in DMSO- $d_{6}$. 


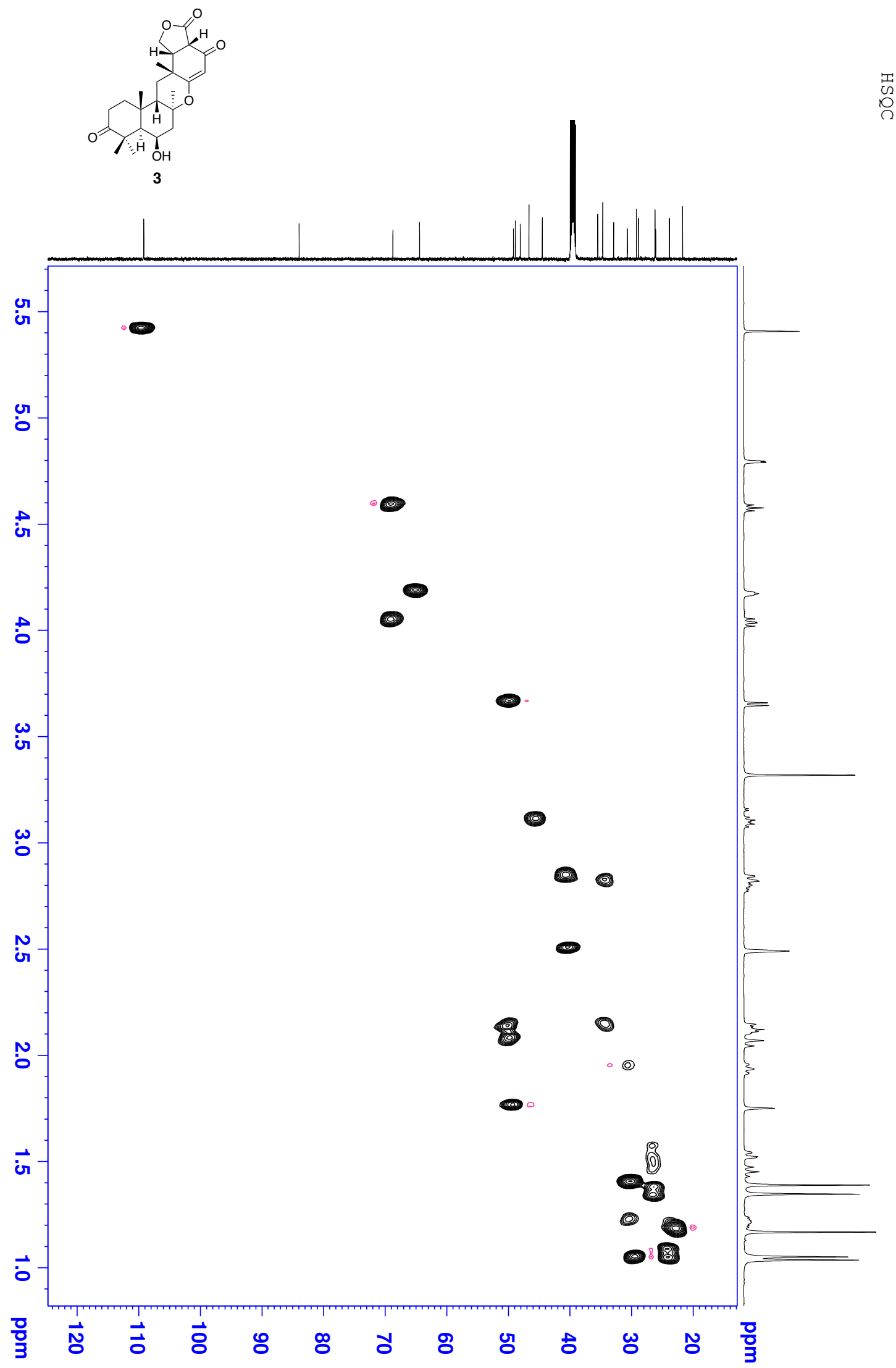

Figure S21. HSQC spectrum of funiculolide C (3) in DMSO- $d_{6}$. 


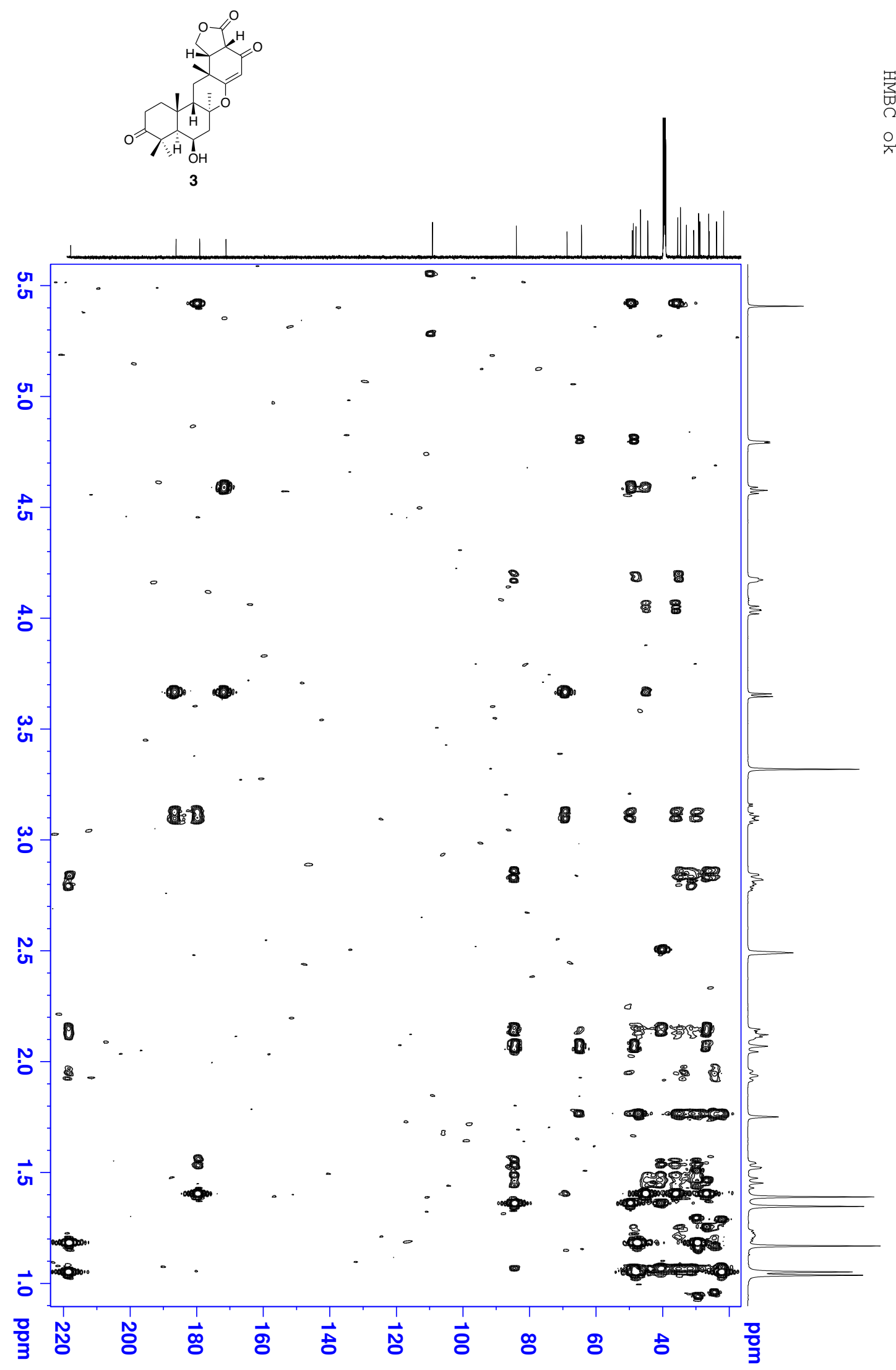

Figure S22. HMBC of funiculolide C (3) in DMSO- $d_{6}$. 


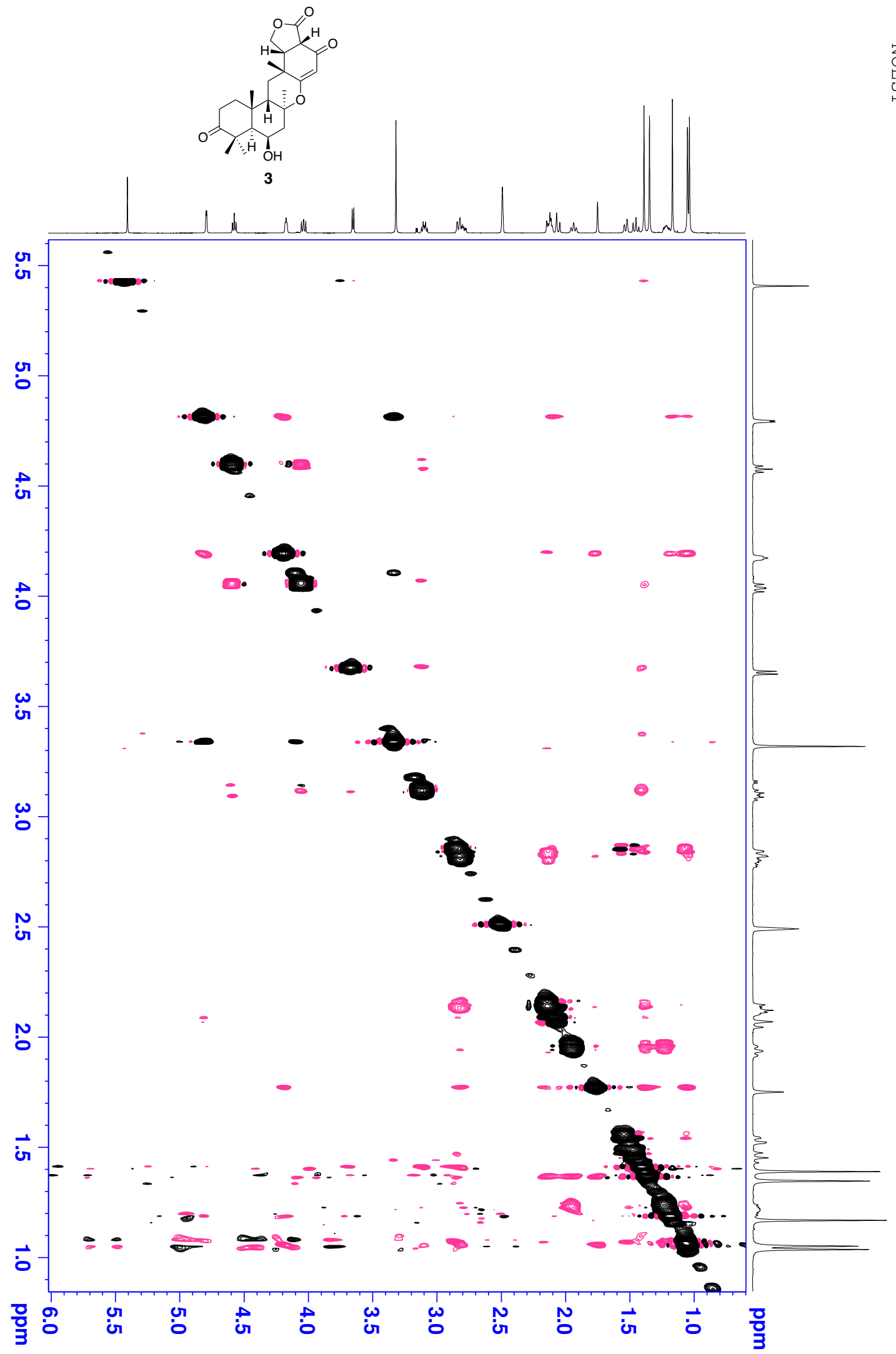

Figure S23. NOESY spectrum of funiculolide C (3) in DMSO- $d_{6}$. 


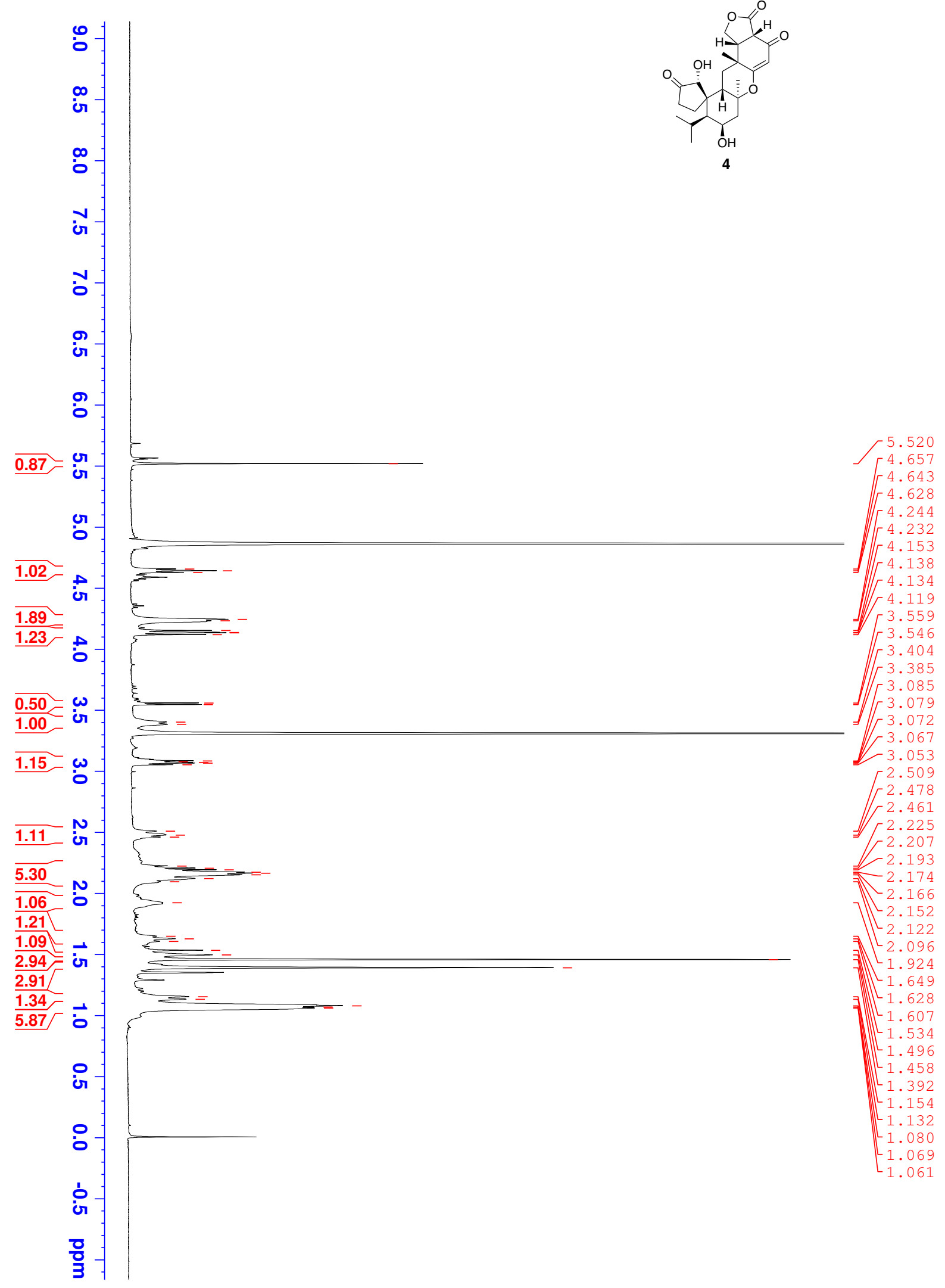

Figure S24. ${ }^{1} \mathrm{H}$ NMR spectrum of funiculolide D (4) in $\mathrm{CD}_{3} \mathrm{OD}$ at $600 \mathrm{MHz}$. 


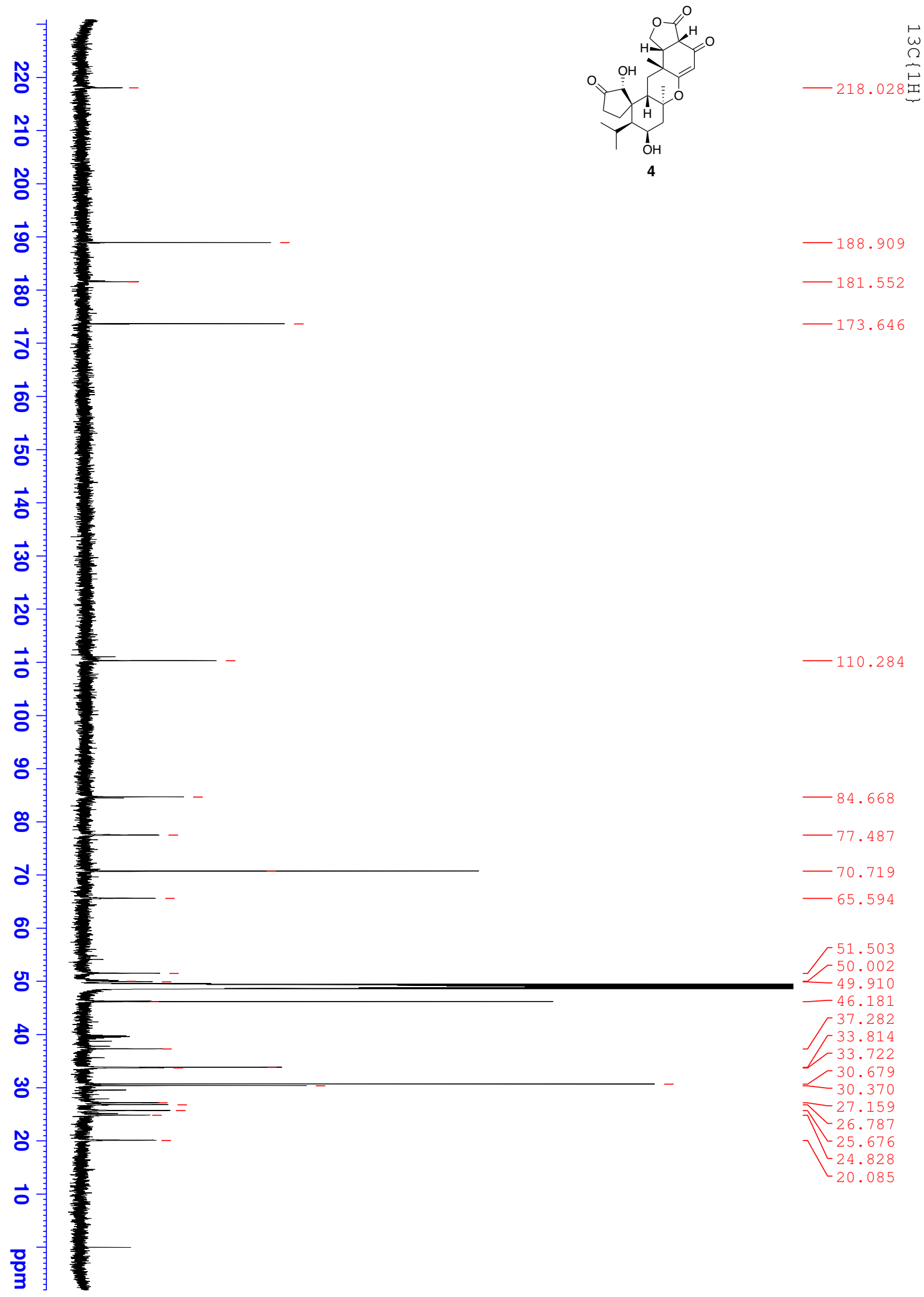

Figure S25. ${ }^{13} \mathrm{C}$ NMR spectrum of funiculolide D (4) in $\mathrm{CD}_{3} \mathrm{OD}$ at $150 \mathrm{MHz}$. 


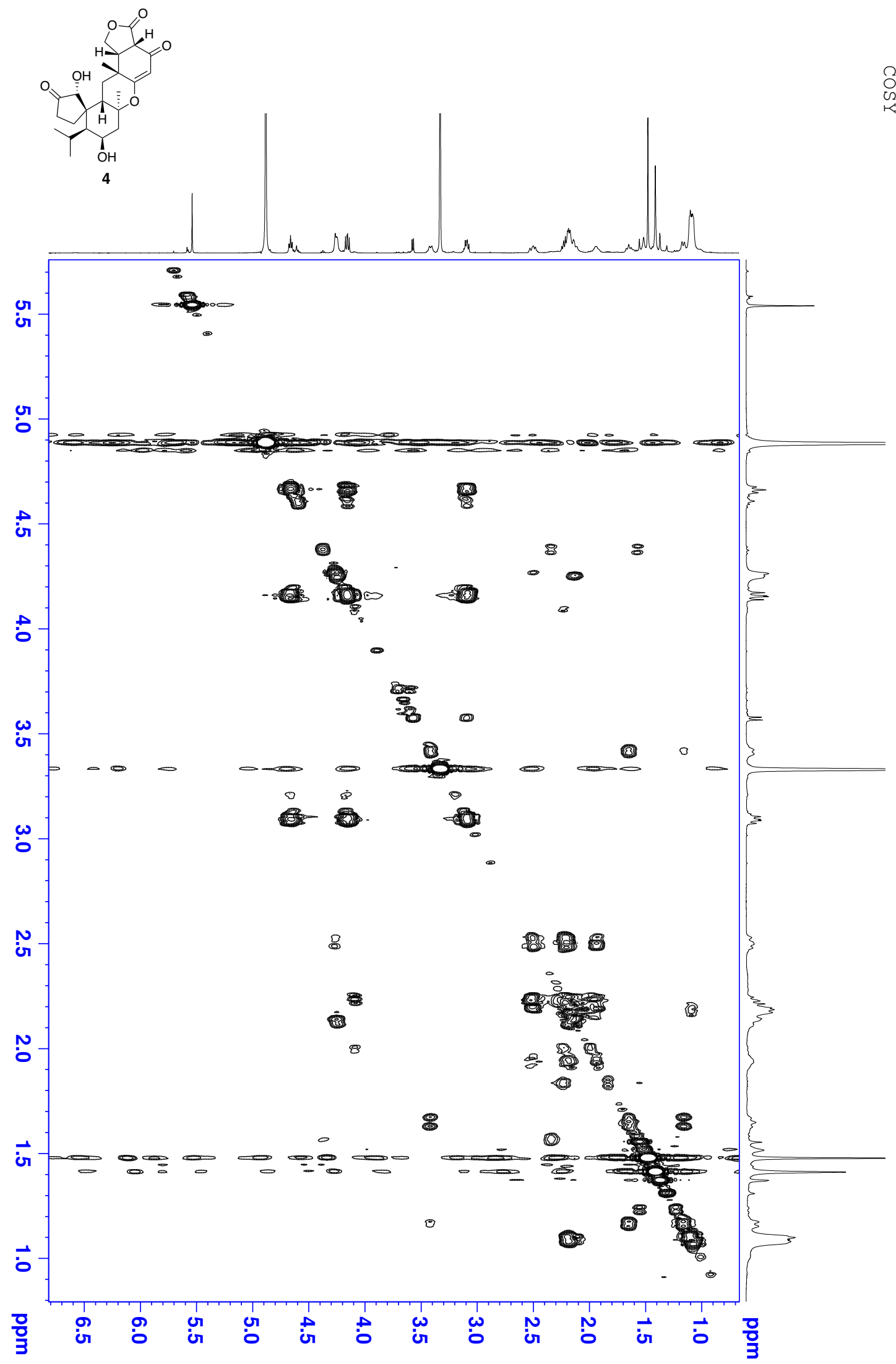

Figure S26. ${ }^{1} \mathrm{H}-{ }^{1} \mathrm{H}$ COSY spectrum of funiculolide D (4) in $\mathrm{CD}_{3} \mathrm{OD}$. 


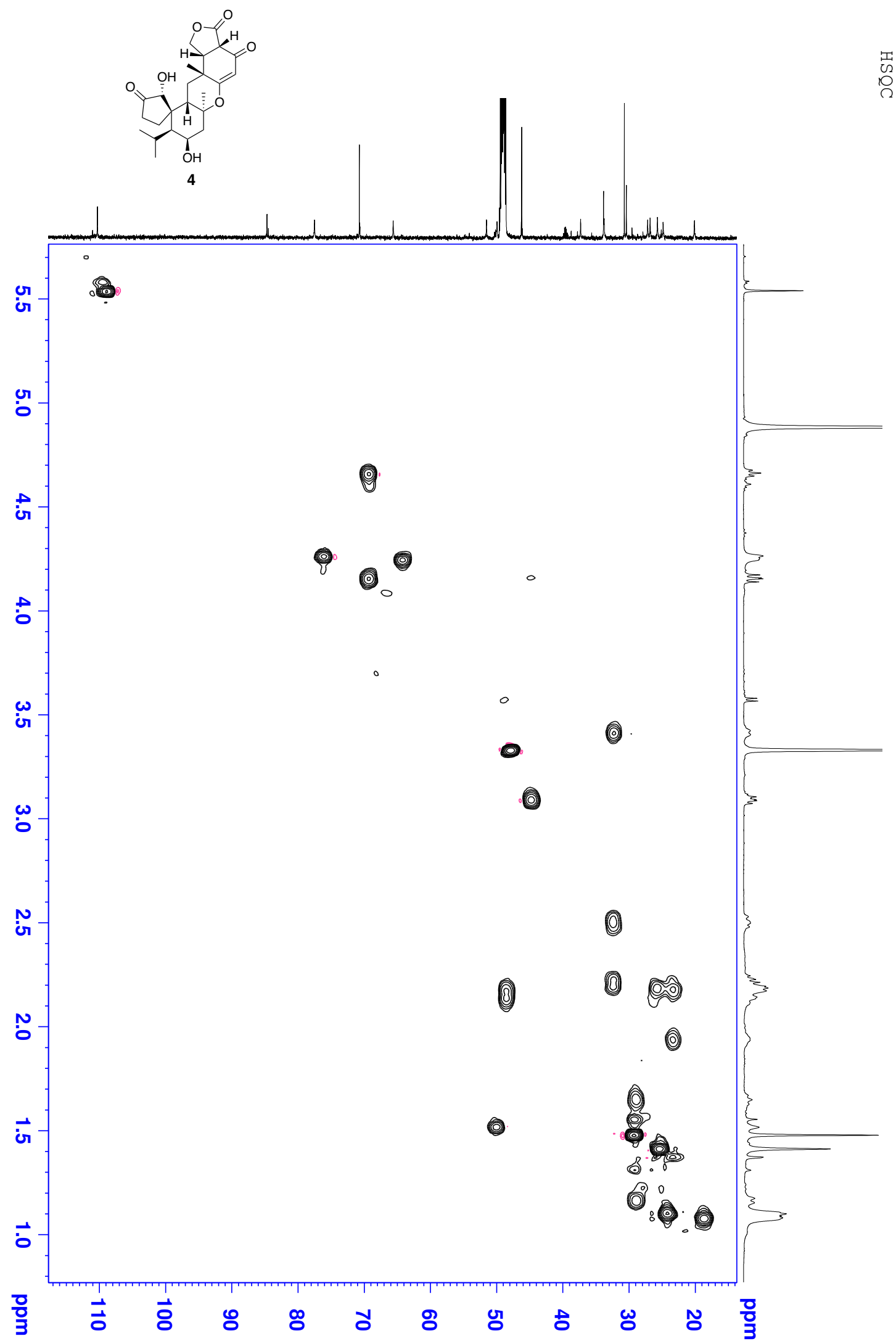

Figure S27. HSQC spectrum of funiculolide D (4) in $\mathrm{CD}_{3} \mathrm{OD}$. 


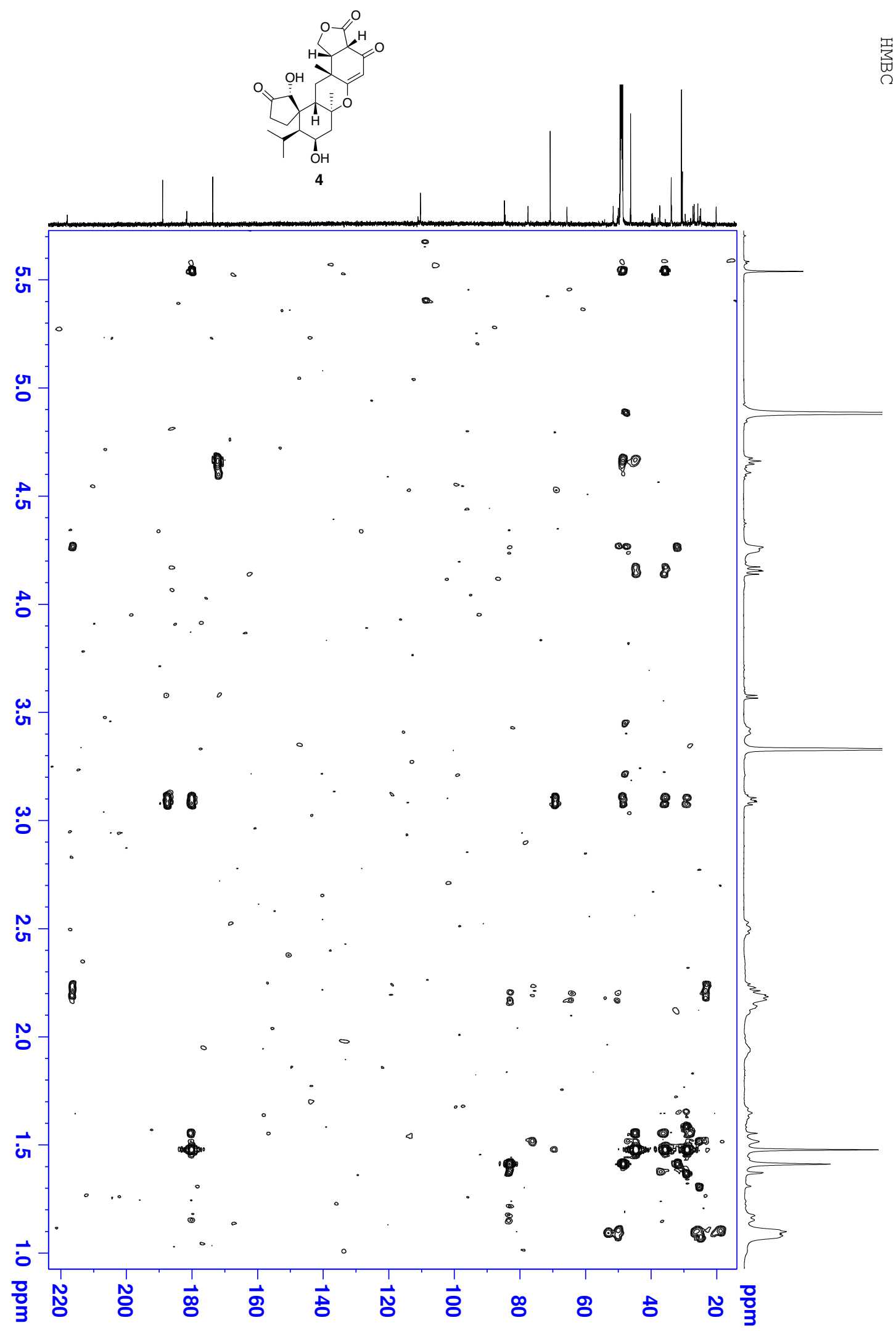

Figure S28. HMBC of funiculolide D (4) in $\mathrm{CD}_{3} \mathrm{OD}$. 


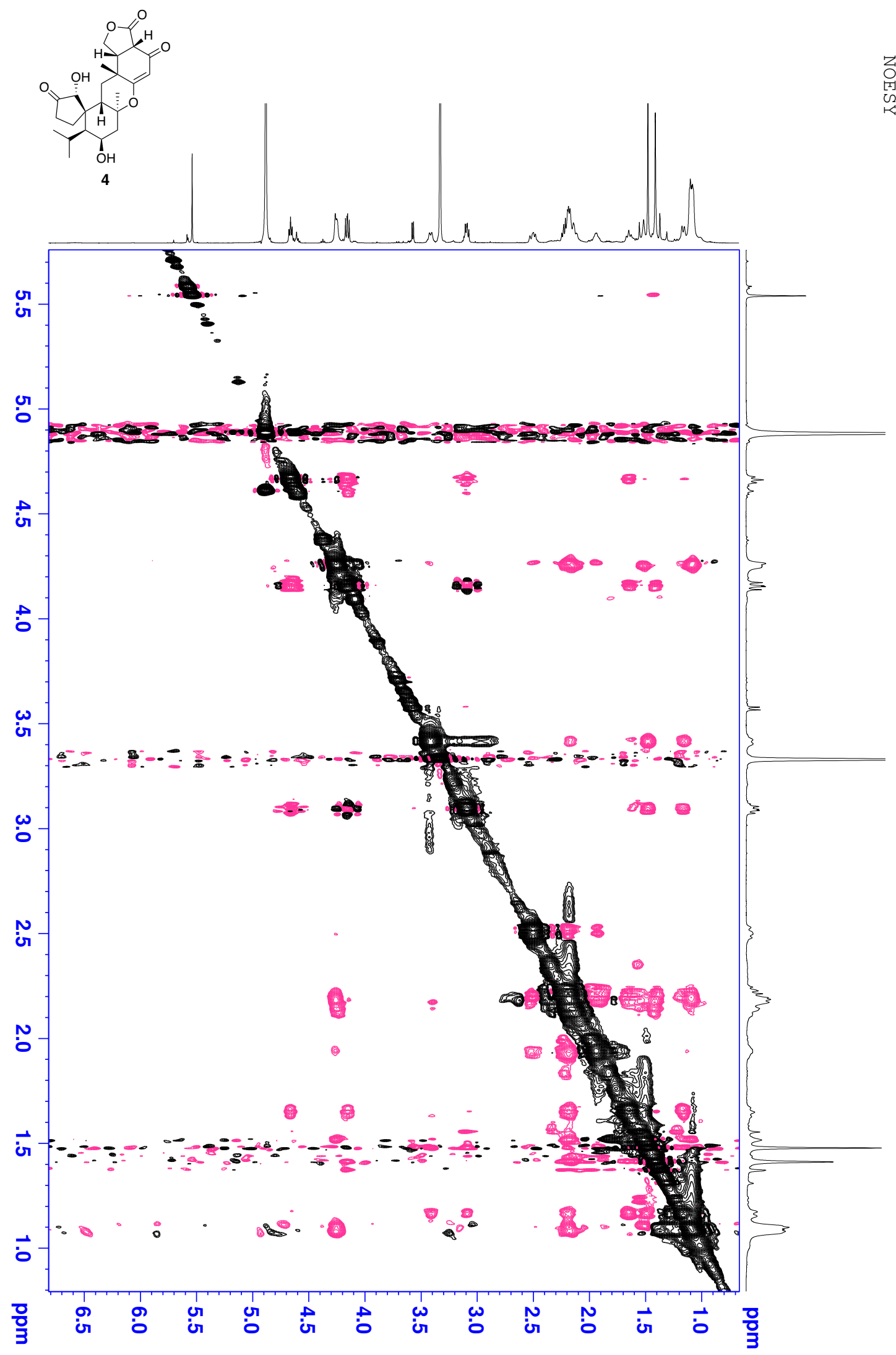

Figure S29. NOESY spectrum of funiculolide D (4) in $\mathrm{CD}_{3} \mathrm{OD}$. 


\section{X-Ray Crystallographic Data}

\section{Funiculolide B (2) (CCDC: 2069886)}

ORTEP view of compound 2 with $50 \%$ probability of thermal ellipsoid.

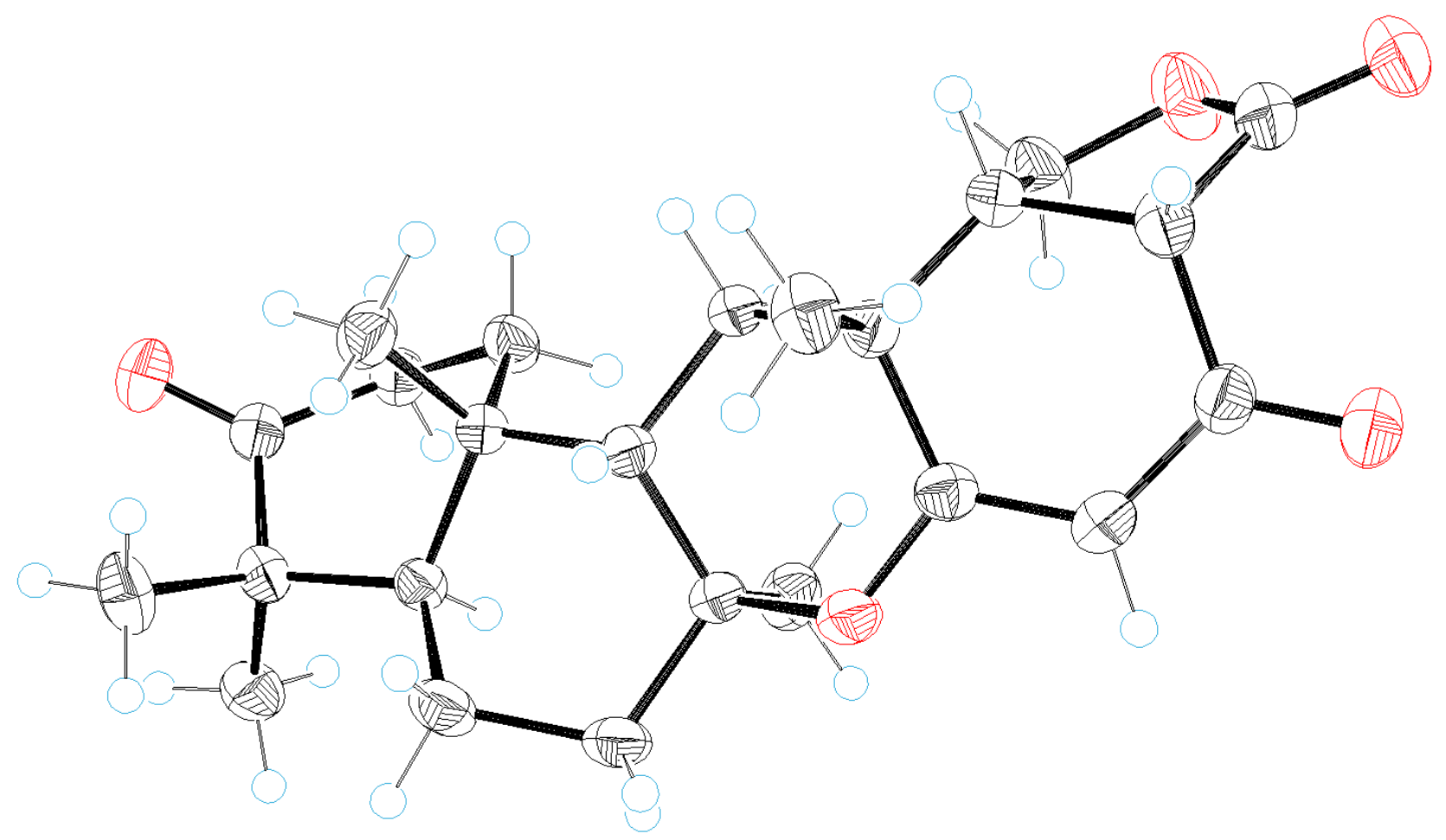

Crystallographic data for funiculolide $B$ (2). $\mathrm{C}_{24} \mathrm{H}_{32} \mathrm{O}_{5}, M=400.49, a=8.7441(5) \AA, b=12.5593(7) \AA, c=$ 19.0261(10) $\AA, \alpha=90^{\circ}, \beta=90^{\circ}, \gamma=90^{\circ}, V=2089.4(2) \AA^{3}, T=243(2) \mathrm{K}$, space group $P 2{ }_{1} 22_{1}, Z=4, \mu(\mathrm{Cu}$ $\mathrm{K} \alpha)=0.708 \mathrm{~mm}^{-1}, 32063$ reflections measured, 4267 independent reflections $\left(R_{\text {int }}=0.0483\right)$. The final $R_{1}$ values were $0.0324(I>2 \sigma(I))$. The final $w R\left(F^{2}\right)$ values were $0.0870(I>2 \sigma(I))$. The final $R_{1}$ values were 0.0326 (all data). The final $w R\left(F^{2}\right)$ values were 0.0872 (all data). The goodness of fit on $F^{2}$ was 1.034. Flack parameter $=0.09(4)$. The crystallographic information file (CIF) for this crystal structure was submitted to The Cambridge Crystallographic Data Centre (CCDC), under reference number 2069886. 


\section{Funiculolide C (3) (CCDC: 2069887)}

ORTEP view of compound 3 with 50\% probability of thermal ellipsoid.

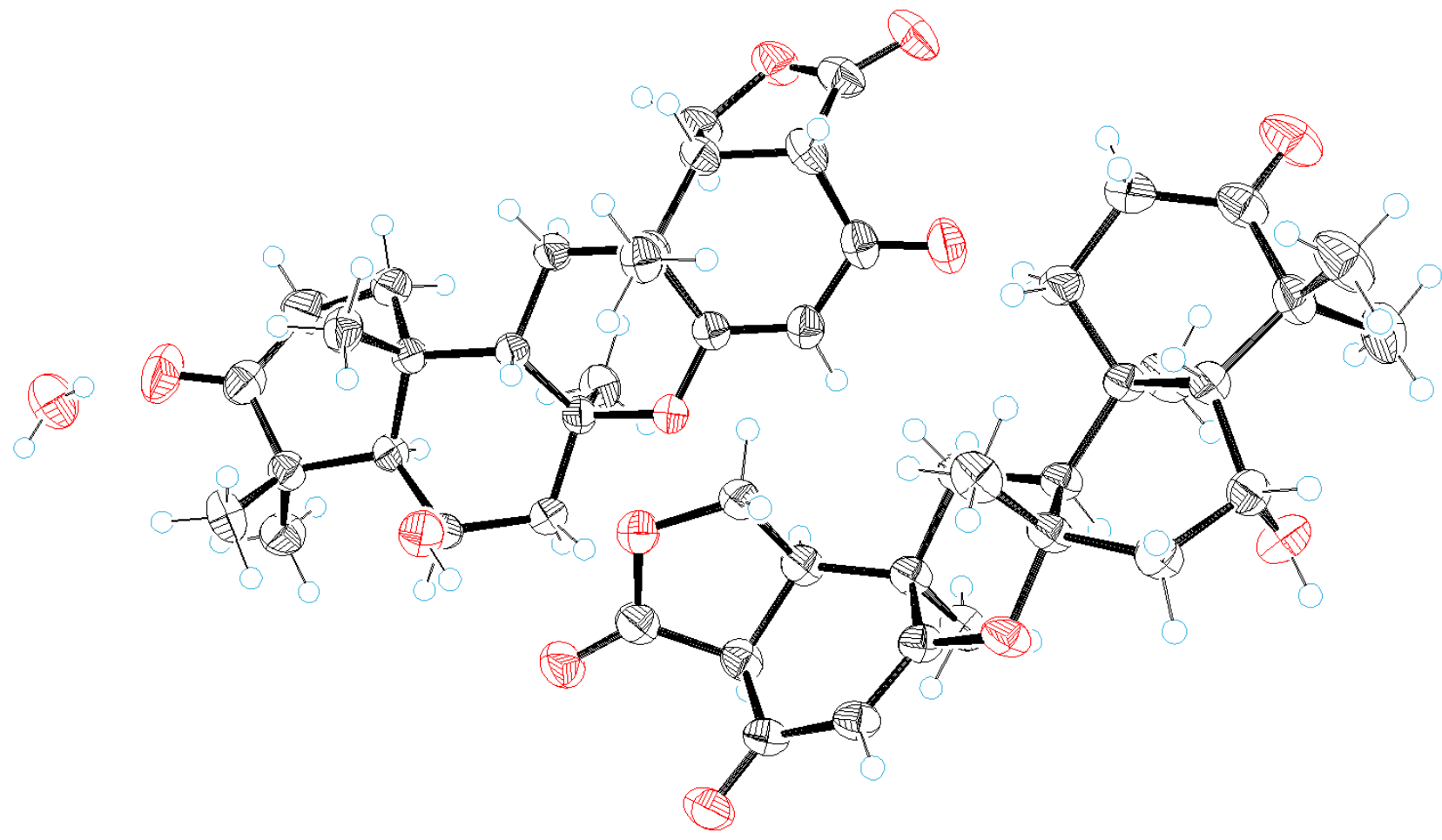

Crystallographic data for funiculolide $C$ (3). $\mathrm{C}_{24} \mathrm{H}_{33} \mathrm{O}_{6.5}, M=425.50, a=8.1738(7) \AA, b=19.0958(18) \AA, c$ $=27.816(3) \AA, \alpha=90^{\circ}, \beta=90^{\circ}, \gamma=90^{\circ}, V=4341.7(7) \AA^{3}, T=243(2) \mathrm{K}$, space group $P 2{ }_{1} 2{ }_{1}{ }_{1}, Z=8, \mu(\mathrm{Cu} \mathrm{K} \alpha)$ $=0.766 \mathrm{~mm}^{-1}, 160928$ reflections measured, 8905 independent reflections $\left(R_{\text {int }}=0.0746\right)$. The final $R_{1}$ values were $0.0345(I>2 \sigma(I))$. The final $w R\left(F^{2}\right)$ values were $0.0907(I>2 \sigma(I))$. The final $R_{1}$ values were 0.0351 (all data). The final $w R\left(F^{2}\right)$ values were 0.0912 (all data). The goodness of fit on $F^{2}$ was 1.023 . Flack parameter $=$ 0.12(3). The crystallographic information file (CIF) for this crystal structure was submitted to The Cambridge Crystallographic Data Centre (CCDC), under reference number 2069887. 


\section{Supplementary References:}

(1) Jin, F. J.; Maruyama, J.; Juvvadi, P. R.; Arioka, M.; Kitamoto, K., Development of a novel quadruple auxotrophic host transformation system by $\arg B$ gene disruption using ade $A$ gene and exploiting adenine auxotrophy in Aspergillus oryzae. FEMS Microbiol. Lett. 2004, 239, 79-85.

(2) Fujii, T.; Yamaoka, H.; Gomi, K.; Kitamoto, K.; Kumagai, C., Cloning and nucleotide sequence of the ribonuclease T1 gene (rntA) from Aspergillus oryzae and its expression in Saccharomyces cerevisiae and Aspergillus oryzae. Biosci. Biotechnol. Biochem. 1995, 59, 1869-1874.

(3) Yamada, O.; Na Nan, S.; Akao, T.; Tominaga, M.; Watanabe, H.; Satoh, T.; Enei, H.; Akita, O., dffA Gene from Aspergillus oryzae encodes L-ornithine $N^{5}$-oxygenase and is indispensable for deferriferrichrysin biosynthesis. J. Biosci. Bioeng. 2003, 95, 82-88.

(4) Jin, F.; Maruyama, J.; Juvvadi, P.; Arioka, M.; Kitamoto, K., Adenine auxotrophic mutants of Aspergillus oryzae: Development of a novel transformation system with triple auxotrophic hosts. Biosci. Biotechnol. Biochem. 2004, 68, 656662.

(5) Kubodera, T.; Yamashita, N.; Nishimura, A., Transformation of Aspergillus sp. and Trichoderma reesei using the pyrithiamine resistance gene (ptrA) of Aspergillus oryzae. Biosci. Biotechnol. Biochem. 2002, 66, 404-406.

(6) Matsuda, Y.; Bai, T.; Phippen, C. B. W.; Nødvig, C. S.; Kjærbølling, I.; Vesth, T. C.; Andersen, M. R.; Mortensen, U. H.; Gotfredsen, C. H.; Abe, I.; Larsen, T. O., Novofumigatonin biosynthesis involves a non-heme iron-dependent endoperoxide isomerase for orthoester formation. Nat. Commun. 2018, 9, 2587. 